TITLE:

\title{
Cryo-EM Structure of the Prostaglandin E Receptor EP4 Coupled to G Protein( Dissertation_全文)
}

$\operatorname{AUTHOR}(S)$ :

Nojima, Shingo

\section{CITATION:}

Nojima, Shingo. Cryo-EM Structure of the Prostaglandin E Receptor EP4 Coupled to G Protein. 京都大学, 2021, 博士(医科学)

ISSUE DATE:

2021-03-23

URL:

https://doi.org/10.14989/doctor.k23113

RIGHT:

DOI: 10.1016/j.str.2020.11.007 


\section{Structure}

\section{Cryo-EM Structure of the Prostaglandin E Receptor EP4 Coupled to G Protein}

\section{Graphical Abstract}

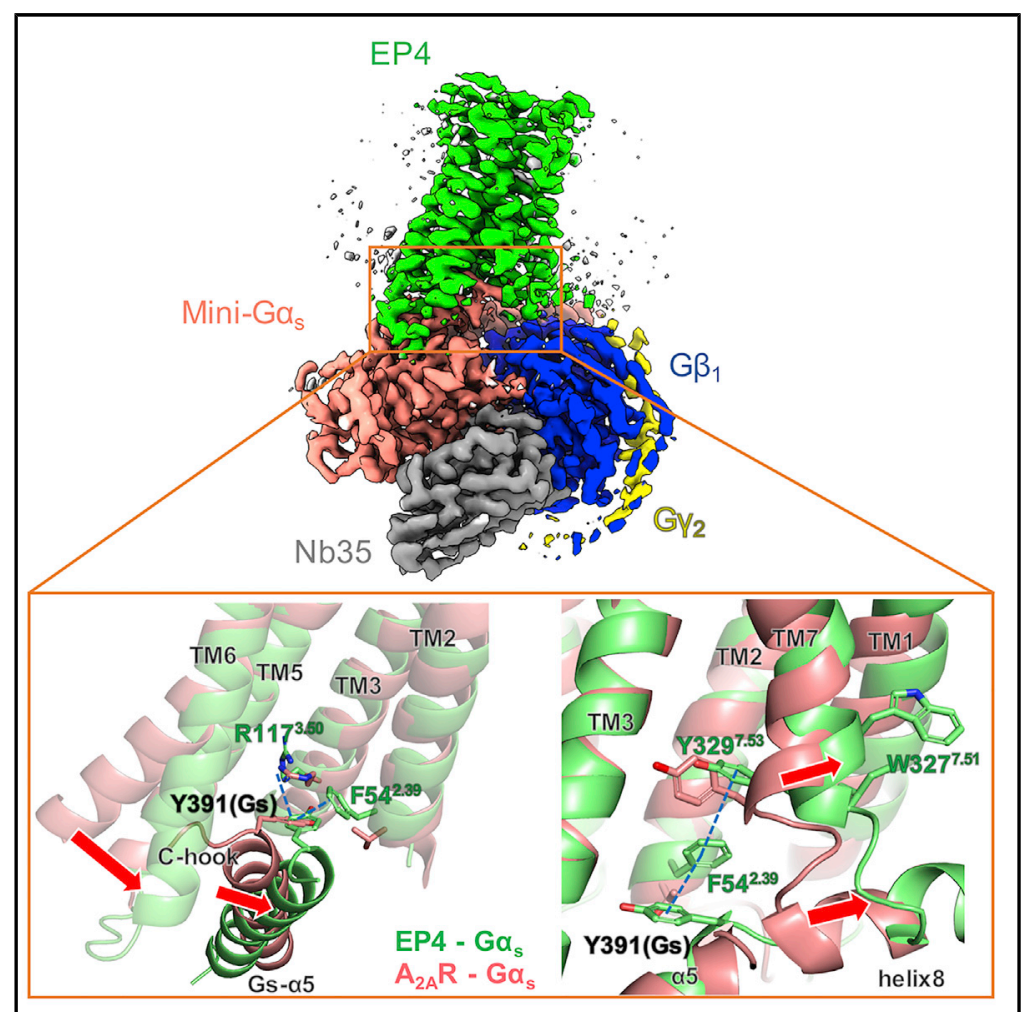

\section{Highlights}

- Cryo-EM structure of EP4-heterotrimeric G protein (Gs) complex with $\mathrm{PGE}_{2}$ at $3.3 \AA$

- Compared with other class A GPCRs bound to Gs, TM6 was shifted smaller

- $\alpha 5$ helix of Gs was inserted toward TM2 of EP4 and the C-terminal hook was unwound

- Structure was formed by conserved residues in prostanoid receptors

\section{Authors}

Shingo Nojima, Yoko Fujita, Kanako Terakado Kimura, ..., So Iwata, Hideki Shigematsu, Takuya Kobayashi

\section{Correspondence}

hideki.shigematsu@riken.jp (H.S.), kobayatk@hirakata.kmu.ac.jp (T.K.)

\section{In Brief}

Nojima and Fujita et al. determined the cryo-EM structure of prostaglandin $E$ receptor EP4 bound to the heterotrimeric $G$ protein and the endogenous ligand $\mathrm{PGE}_{2}$. The structure reveals the novel binding mode between GPCRs and Gs, which provides us the information for the structure-based activation mechanism of prostanoid receptors. 


\title{
Structure
}

\section{Cryo-EM Structure of the Prostaglandin E Receptor EP4 Coupled to G Protein}

\author{
Shingo Nojima, ${ }^{1,6}$ Yoko Fujita, ${ }^{2,3,6}$ Kanako Terakado Kimura, ${ }^{1}$ Norimichi Nomura, ${ }^{1}$ Ryoji Suno, ${ }^{1,4}$ Kazushi Morimoto, ${ }^{1}$ \\ Masaki Yamamoto, ${ }^{5}$ Takeshi Noda, ${ }^{2,3}$ So Iwata, ${ }^{1}$ Hideki Shigematsu, ${ }^{5, *}$ and Takuya Kobayashi ${ }^{1,4,7, *}$ \\ ${ }^{1}$ Department of Cell Biology, Graduate School of Medicine, Kyoto University, Kyoto, Kyoto 606-8501, Japan \\ 'Laboratory of Ultrastructural Virology, Institute for Frontier Life and Medical Sciences, Kyoto University, Kyoto, Kyoto 606-8507, Japan \\ ${ }^{3}$ Laboratory of Ultrastructural Virology, Division of Integrated Life Science, Graduate School of Biostudies, Kyoto University, Kyoto, Kyoto \\ 606-8507, Japan \\ ${ }^{4}$ Department of Medical Chemistry, Kansai Medical University, Hirakata, Osaka 573-1010, Japan \\ ${ }^{5}$ RIKEN Spring-8 Center, Life Science Research Infrastructure Group, Sayo-gun, Hyogo 679-5148, Japan \\ ${ }^{6}$ These authors contributed equally \\ ${ }^{7}$ Lead Contact \\ *Correspondence: hideki.shigematsu@riken.jp (H.S.), kobayatk@hirakata.kmu.ac.jp (T.K.) \\ https://doi.org/10.1016/j.str.2020.11.007
}

\section{SUMMARY}

Prostaglandin E receptor EP4, a class A G protein-coupled receptor (GPCR), is a common drug target in various disorders, such as acute decompensated heart failure and ulcerative colitis. Here, we report the cryoelectron microscopy (cryo-EM) structure of the EP4-heterotrimeric G protein (Gs) complex with the endogenous ligand at a global resolution of $3.3 \AA$. In this structure, compared with that in the inactive EP4 structure, the sixth transmembrane domain is shifted outward on the intracellular side, although the shift is smaller than that in other class A GPCRs bound to Gs. Instead, the C-terminal helix of Gs is inserted toward TM2 of EP4, and the conserved C-terminal hook structure formsthe extended state. These structural features are formed by the conserved residues in prostanoid receptors (Phe54 $4^{2.39}$ and $\operatorname{Trp} 327^{7.51}$ ). These findings may be important for the thorough understanding of the G protein-binding mechanism of EP4 and other prostanoid receptors.

\section{INTRODUCTION}

Prostanoids are lipid mediators that are involved in various physiological processes, including inflammation, cardiovascular homeostasis, fertilization, and parturition (Hirata and Narumiya, 2011), and major prostanoids are metabolized from arachidonic acid. Cyclooxygenase oxidizes arachidonic acid to prostaglandin (PG) $G_{2}$, which is then reduced to $P G H_{2}$. Subsequently, $P G_{2}$ is converted to $\mathrm{PGD}_{2}, \mathrm{PGE}_{2}, \mathrm{PGF}_{2 \alpha}, \mathrm{PGI}_{2}$, or thromboxane $\mathrm{A}_{2}$ by respective synthases. Prostanoid signals are transmitted via class A G protein-coupled receptors (GPCRs), namely, DP1, DP2, EP1, EP2, EP3, EP4, FP, IP, and TP (Hirata and Narumiya, 2011). These receptors are homologous, except for DP2, which is a member of the leukocyte chemoattractant family. EP1, EP2, $E P 3$, and EP4 are all receptors for $P G E_{2}$, although the $G$ proteins coupled to these receptors vary. Signaling assays have shown that EP1 is coupled to Gq, EP2, and EP4 are coupled to Gs, and EP3 is primarily coupled to Gi (Fujino and Regan, 2006; Inoue et al., 2019). G proteins transmit signals via different downstream signaling pathways. Gs, which is coupled to EP4, increases the concentration of cAMP by activating adenylyl cyclase.

EP4 is expressed in various tissues, including the thymus, ileum, lung, spleen, adrenal gland, and kidney (Bastien et al.,
1994; Guan et al., 1996; Honda et al., 1993; Sando et al., 1994). As EP4 signaling is involved in carcinogenesis, cardiac hypertrophy, vasodilation, vascular remodeling, gastrointestinal homeostasis, renal function, and female reproductive function (Yokoyama et al., 2013), it is a candidate drug target for some diseases. Administration of EP4 agonist restored bone mass and strength in rats subjected to ovariectomy or immobilization, which normally cause loss of bone mass (Yoshida et al., 2002). This indicates that EP4 agonists can be potentially used as drugs for osteoporosis. The EP4 agonists ONO-4232, KAG-308, and CJ-023423 have been tested in clinical trials for acute decompensated heart failure, ulcerative colitis, and canine osteoarthritis, respectively (Rausch-Derra et al., 2016; Ward et al., 2016; Watanabe et al., 2015). In addition, the EP4 antagonist E7046 is in a phase I trial for anticancer agents (Bao et al., 2015).

Recent studies have revealed the structures of the active and inactive states of various lipid receptors, namely, lysophospholipid receptors $\left(\mathrm{S} 1 \mathrm{P}_{1}, \mathrm{LPA}_{1}\right.$, and $\left.\mathrm{LPA}_{6}\right)($ Chrencik et al., 2015; Hanson et al., 2012; Taniguchi et al., 2017), cannabinoid receptors $\left(\mathrm{CB}_{1}\right.$ and $\left.\mathrm{CB}_{2}\right)$ (Hua et al., 2016, 2017, 2020; Kumar et al., 2019; Shao et al., 2016), leukotriene receptors (cysLT $T_{1}$, cys $_{2} T_{2}$, and BLT1) (Gusach et al., 2019; Hori et al., 2018; Luginina et al., 2019), prostanoid receptors (DP2, EP3, EP4, and TP) (Audet 
A

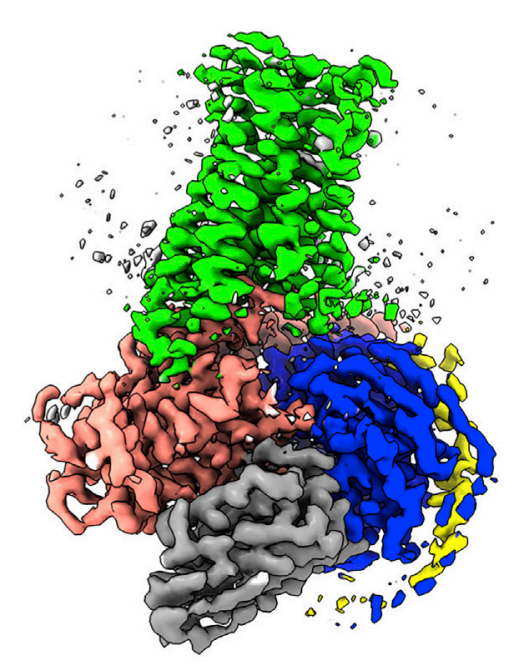

B

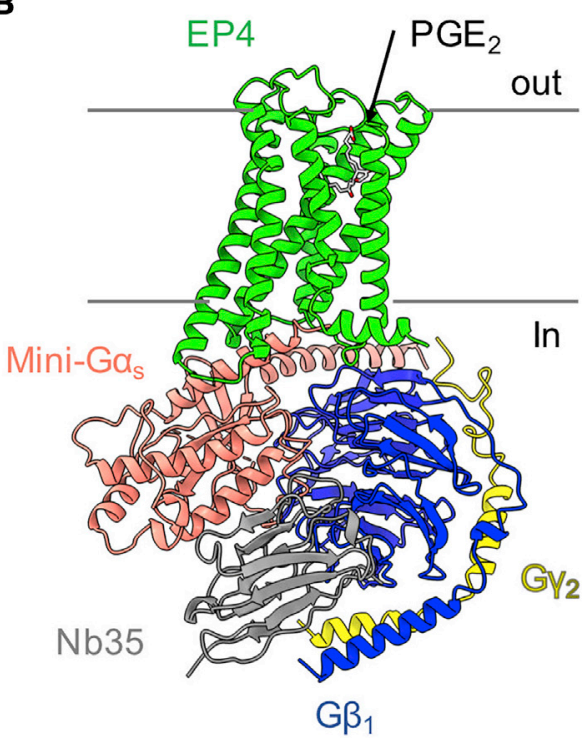

Figure 1. EM Map and 3D Model of the PGE ${ }_{2}$-EP4-Gs $\beta_{1} \gamma_{2}$-Nb35 Complex

(A) The EM map of the EP4 complex at a resolution of $3.3 \AA$. The contour level of the map is set to 0.030 in order not to show the density of the micelle. The map derived from EP4, mini-Gs, $G \beta_{1}, G \gamma_{2}$, and $\mathrm{Nb} 35$ is shown in green, light red, blue, yellow, and gray, respectively.

(B) The 3D model determined based on the EM map. The models are colored by chain as in (A). The gray stick indicates $\mathrm{PGE}_{2}$.

See also Figures S1-S4. et al., 2019; Fan et al., 2019; Morimoto et al., 2019; Toyoda et al., 2019; Wang et al., 2018), and platelet-activating factor receptor (Cao et al., 2018). Among these, structural information of the inactive form revealed common structural feature of lipid receptors. The extracellular loop 2 (ECL2) or N-terminal loop forms the lid structure and covers the ligand-binding pocket in many lipid receptors. Instead, large gaps exist on the transmembrane side through which the ligands are able to access the ligand-binding pocket in lipid receptors (Audet and Stevens, 2019). In particular, in EP4 and TP, gaps are observed between TM1 and TM7. The crystal structures of EP3 bound to the endogenous agonist $\mathrm{PGE}_{2}$ or misoprostol-FA have been elucidated (Audet et al., 2019; Morimoto et al., 2019). In these agonist-bound structures, the gaps described above are closed. Based on this structural information, the helices forming the gap are thought to be flexible, and the gap appears to close after the agonist binds to the orthosteric ligand-binding site.

Structural features also exist at the receptor-G protein interface. GPCR activation generally proceeds in five steps: (1) the ligand binds to a GPCR on the extracellular side; (2) the conformation of the GPCR changes from an inactive to an active form; (3) conformational changes enable the heterotrimeric GDP-bound $G$ protein $(\mathrm{G} \alpha, \mathrm{G} \beta$, and $\mathrm{G} \gamma)$ to access the GPCR on the intracellular side; (4) GTP exchange occurs in the Raslike GTPase domain of $\mathrm{G} \alpha$; and (5) $\mathrm{G} \alpha$ and $\mathrm{G} \beta-\mathrm{G} \gamma$ heterodimers dissociate and transmit the signals to downstream factors (Gilman, 1987). Previous studies have successfully prepared stable GPCR-G protein complexes using GTP-free G protein to prevent the $G$ protein from exchanging GTP and dissociating. Using these methods, the structures of $\beta_{1}$ and $\beta_{2}$ adrenergic receptors $\left(\beta_{1} A R\right.$ and $\left.\beta_{2} A R\right)$, adenosine $A_{2 A}$ receptor $\left(A_{2 A} R\right)$, and class $A$ orphan GPCR (GPR52) have been determined to be class A GPCR-Gs complexes (García-Nafría et al., 2018; Lin et al., 2020; Rasmussen et al., 2011; Su et al., 2020; Zhang et al., 2020). Among these, the outward shift of the sixth transmembrane domain (TM6) of GPCR and insertion of the C-termilix of Gs via hydrogen bonds and hydrophobic interactions, while TM6 interacts with the C-terminal loop (called the C-terminal hook) of Gs via hydrophobic interactions in these receptor-Gs complexes. The gap structure of lipid receptors and this activation feature of general GPCRs might be applicable to EP4. However, structural evidence of the active state EP4 is not available. Structural information regarding prostanoid receptor binding to $\mathrm{G}$ protein is also not available, because of which the coupling mechanism with $G$ protein has not been revealed.

Here, we determined a cryoelectron microscopy (cryo-EM) structure of the PGE 2 -EP4-Gs $\beta_{1} \gamma_{2}-\mathrm{Nb} 35$ complex at a resolution of $3.3 \AA$. This structure revealed not only the structural changes in EP4 when it transitions from the inactive state to the active state, but also the unique binding mode between GPCR and G protein which seems to be common in prostanoid receptors.

\section{RESULTS}

\section{Cryo-EM Structure of the PGE $2-E P 4-G s \beta_{1} \gamma_{2}-\mathrm{Nb} 35$ Complex}

To prepare a stable EP4-Gs complex, EP4, mini-Gs, G $\beta_{1}-G \gamma_{2}$ heterodimer, and nanobody (Nb35) (Rasmussen et al., 2011) were used. The expression construct of EP4 was essentially the same as that used in a previous crystallographic study (Toyoda et al., 2019), except that the two thermo-stabilizing point mutations Ala62 ${ }^{2.47}$ Leu and Gly $106^{3.39}$ Arg were not introduced, as these mutations shift the conformational equilibrium toward an inactive state and prevent $\mathrm{PGE}_{2}$ binding. In brief, the human EP4 receptor was modified to add the signal sequence of hemagglutinin, followed by a FLAG epitope at the $\mathrm{N}$ terminus, and the $\mathrm{His}_{8}$ tag at the $\mathrm{C}$ terminus, both flanked by the $3 \mathrm{C}$ cleavage site. The N-terminal residues (residues 1-3), C-terminal residues (residues 367-488), and ICL3 (residues 218-259) were deleted, and the $\mathrm{N}$-linked glycosylation sites (Asn7 and Asn177) were mutated to glutamine. Using the signaling assay, it has been confirmed 


\begin{tabular}{|c|c|}
\hline & $\begin{array}{l}\text { PGE }_{2}-E P 4-G s \beta_{1} \gamma_{2}-N b 35 \text { Complex } \\
\text { at } 3.3 \AA \text { (EMDB: EMD-30608) } \\
\text { (PDB: 7D7M) }\end{array}$ \\
\hline \multicolumn{2}{|l|}{ Data Collection and Processing } \\
\hline Magnification & 105,000 \\
\hline Voltage (kV) & 300 \\
\hline Electron exposure $\left(\mathrm{e}-/ \AA^{2}\right)$ & 50.0 \\
\hline Defocus range $(\mu \mathrm{m})$ & $-0.6 \sim-1.8$ \\
\hline Pixel size $(\AA)$ & 0.85 \\
\hline No. of initial particle images & $2,796,263$ \\
\hline No. of final particle images & 178,217 \\
\hline $\begin{array}{l}\text { Map resolution (Å) } \\
\text { FSC threshold }\end{array}$ & $\begin{array}{l}3.3 \\
0.143\end{array}$ \\
\hline Map resolution range $(\AA)$ & $3.13-4.26$ \\
\hline \multicolumn{2}{|l|}{ Refinement } \\
\hline Initial model used (PDB code) & $\begin{array}{l}\text { 6YWY (EP4) } \\
6 \mathrm{GDG}\left(\mathrm{Gs}, \mathrm{G} \beta_{1}, \mathrm{G} \gamma_{2}, \mathrm{Nb35}\right)\end{array}$ \\
\hline $\begin{array}{l}\text { Model resolution }(\AA) \\
\text { FSC threshold }\end{array}$ & $\begin{array}{l}3.6 \\
0.5\end{array}$ \\
\hline Map sharpening $B$ factor $\left(\AA^{2}\right)$ & -106.26 \\
\hline $\begin{array}{l}\text { Model composition } \\
\text { Non-hydrogen atoms } \\
\text { Protein residues } \\
\text { Ligands }\end{array}$ & $\begin{array}{l}7,326 \\
1,031 \\
1\end{array}$ \\
\hline \multicolumn{2}{|l|}{ B factors $\left(\AA^{2}\right)$} \\
\hline $\begin{array}{l}\text { Protein } \\
\text { Ligand }\end{array}$ & $\begin{array}{l}39.2 \\
89.0\end{array}$ \\
\hline \multicolumn{2}{|l|}{ RMSD } \\
\hline $\begin{array}{l}\text { Bond lengths }(\AA) \\
\text { Bond angles }\left({ }^{\circ}\right)\end{array}$ & $\begin{array}{l}0.01 \\
0.98\end{array}$ \\
\hline \multicolumn{2}{|l|}{ Validation } \\
\hline MolProbity score & 1.5 \\
\hline Clashscore & 9.6 \\
\hline Poor rotamers (\%) & 0.00 \\
\hline \multicolumn{2}{|l|}{ Ramachandran plot (\%) } \\
\hline Favored & 98.7 \\
\hline Allowed & 1.3 \\
\hline Disallowed & 0.0 \\
\hline
\end{tabular}

that the expression construct maintained Gs signaling (Toyoda et al., 2019). EP4 was purified and subsequently mixed with $\mathrm{PGE}_{2}$, the mini-Gs heterotrimer (mini-Gs399 [García-Nafría et al., 2018], $G \beta_{1}$, and $G \gamma_{2}$ ), and Nb35, which stabilizes the GPCR-Gs complex. Surplus components were removed using gel filtration (Figure S1).

Vitrified EP4 complexes were imaged by single-particle cryoEM using a Titan Krios G3i microscope equipped with a K3 camera. Initially, 254,883 particles were used to calculate threedimensional (3D) reconstruction with a global resolution of $3.4 \AA$. The first attempt at model building was performed based on this map. The initial 3D model of the EP4-Gs $\beta_{1} \gamma_{2}-\mathrm{Nb} 35 \mathrm{com}-$ plex can be generated using this map. To improve the signal-tonoise ratio at the binding site of EP4 and Gs, focused classification without alignment was performed with signal subtraction us- ing the mask generated for the EP4-Gs interface fitted on the first map. One of the four 3D classes from $68.96 \%$ of total particles showed better representation of the density around the EP4Gs interface in the refined 3D model by using particles, after reverting the signal (Figures $1 \mathrm{~A}$ and $\mathrm{S} 2$ ). The global resolution of this map is reported to be $3.3 \AA$. On this map, the density isolated compared with the density of the protein appeared around the middle of TM1 and TM2 of EP4, and density that was not isolated but clearly extruded from the model of protein also appeared near the isolated density. When the crystal structure of EP3 bound to $\mathrm{PGE}_{2}$ (Morimoto et al., 2019) was superposed on the initial 3D model of the EP4-Gs $\beta_{1} \gamma_{2}-\mathrm{Nb} 35$ complex, the isolated density overlapped with the five-membered carbon ring of $\mathrm{PGE}_{2}$ and the extruded density overlapped with the alkyl side chain of the $\mathrm{PGE}_{2}$, called the $\omega$ chain (Figure S3). Previous 
A

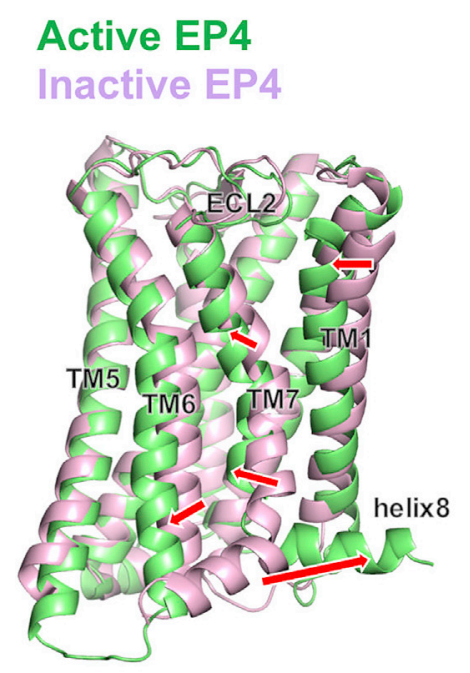

B

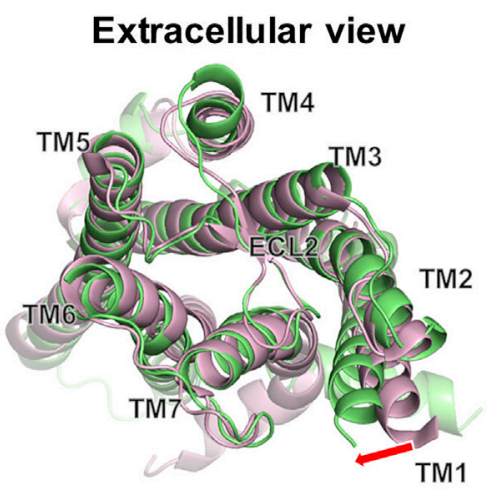

C

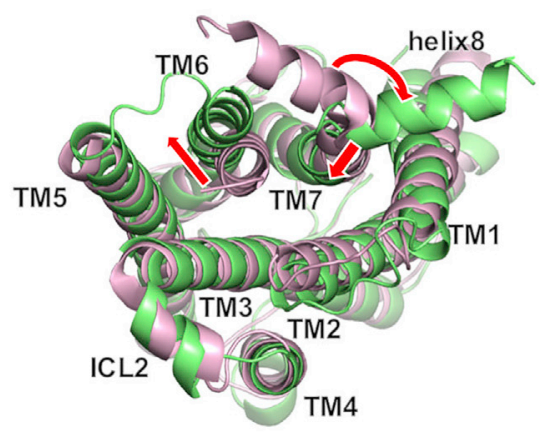

Figure 2. Structural Comparison between Active and Inactive EP4

(A) Side view, (B) extracellular view, and (C) intracellular view. Green and pink cartoons indicate the active and inactive EP4s (PDB: 5YWY), respectively. The conformational changes are shown by red arrows.

mined to be an inactive state (Toyoda et al., 2019). There were four major conformational changes between the two structures (Figure 2). (1) Inactive EP4 harbored a gap between TM1 and TM7 on the extracellular side, which was closed in the active state EP4. (2) The TM6 of the active state EP4 was shifted toward the outside of the receptor on the intracellular side. (3) TM7 was attracted to the receptor on the middle and intracellular sides. These three differences are similar to the conformational changes observed upon transition from the inactive state to the active state of cannabinoid receptors $\left(\mathrm{CB}_{1}\right.$ and $\left.\mathrm{CB}_{2}\right)$ (Hua et al., 2016, 2017, 2020; Kumar et al., 2019; Shao et al., 2016). (4) Compared with that of the inactive state EP4, helix 8 of the active state EP4 was extended in a different direction, with an

studies revealed that the residues of EP4 corresponding to the residues of EP3 bound to the carboxyl group of $P G E_{2}$ are also involved in $\mathrm{PGE}_{2}$ binding, based on the binding assay (Morimoto et al., 2019; Toyoda et al., 2019), thus it could be speculated that the $\mathrm{PGE}_{2}$-binding mode of EP4 is similar to that of EP3. Therefore, the $P G E_{2}$ model in the EP4-Gs $\beta_{1} \gamma_{2}-\mathrm{Nb} 35$ complex was initially built based on the crystal structure of $P G E_{2}$. The final 3D model of the PGE $E_{2}$-EP4-Gs $\beta_{1} \gamma_{2}-\mathrm{Nb} 35$ complex was built and refined on the map with a global resolution of $3.3 \AA$ (Figures $1 \mathrm{~B}$ and S4; Table 1). The map allowed accurate placement of the residues in the regions of Ser19-Cys345 (except for ICL3) of EP4, Gln12-Gln59, Thr204-Asn254, and Arg265-Leu393 of Gs, and Asp5-Asn340 of $\mathrm{G} \beta_{1}$, Gln11-Lys64 of $\mathrm{G} \gamma_{2}$, and Gln1-Ser128 of Nb35.

The active EP4 complex adopted the typical architecture of the activated class A GPCR conformation. Gs, $G \beta_{1}, G \gamma_{2}$, and $\mathrm{Nb} 35$ formed a heterotetrameric complex, which exhibited almost the same structure as the Gs $\beta_{1} \gamma_{2}-\mathrm{Nb} 35$ complex bound to $A_{2 A} R$ (García-Nafría et al., 2018) (root-mean-square deviation $=0.876 \AA$ for $669 \mathrm{C} \alpha$ atoms). EP4 adopted an intracellular open state due to the outward shift of TM6. Similar to other activated class A GPCRs, EP4 and the Gs $\beta_{1} \gamma_{2}-\mathrm{Nb} 35$ complex formed a complex by the insertion of the C-terminal helix $(\alpha 5)$ of Gs into the intracellular side of EP4.

\section{Conformational Transition from an Inactive State to Active State of EP4}

The 3D model of the active state EP4 was compared with the crystal structure of antagonist-bound EP4, previously deter- angular difference of approximately $113^{\circ}$. The difference of helix 8 may be a crystallization artifact, as helix 8 was found to be involved in crystal packing in inactive EP4. Whether the difference of helix 8 is artifact or not, the conformational transition of TM1, TM6, TM7 of EP4 indicates that the conformational transition of EP4 from the inactive to the active state is typical of that of other lipid receptors.

\section{PGE $_{2}$-Binding Site}

The five-member carbon ring of $\mathrm{PGE}_{2}$ was located around Met27 $7^{1.42}$, Thr69 ${ }^{2.54}$, and Ser73 $3^{2.58}$ (Figure $3 \mathrm{~A}$ ). The $\omega$ chain of $\mathrm{PGE}_{2}$ was extended to the side pocket formed by helices TM3, TM5, and ECL2. The density of the carboxyl side chain of $\mathrm{PGE}_{2}$, called an $\alpha$ chain, did not appear on the EM map, but the previous studies revealed that Tyr $80^{2.65}$, Thr168 ${ }^{\mathrm{ECL} 2}$, and $\mathrm{R} 316^{7.40}$ of EP4 were involved in $\mathrm{PGE}_{2}$ binding by binding assay and these residues corresponded to the residues of EP3 bound to the carboxyl group of $\mathrm{PGE}_{2}$ (Toyoda et al., 2019). Therefore, the $\alpha$ chain of $\mathrm{PGE}_{2}$ was placed around TM1, TM2, TM7, and ECL2 on the extracellular side (Figure $3 \mathrm{~B}$ ). The residues related to signal activity were validated using the signaling assay with EP4 site-directed mutants. To evaluate Gs-signaling activity, the concentration of cAMP after adding PGE 2 in HEK293 cells was traced using the GloSensor cAMP assay (Promega). In this assay, the luminescence caused by the activation of CAMP-dependent luciferase was counted. Based on the results of this assay, the mutation of the residues at the orthosteric ligand-binding site, Phe2 $4^{1.39}$, Met2 $7^{1.42}$, Thr69 $9^{2.54}$, Ser73 $3^{2.58}$, Thr76 ${ }^{2.61}$, Tyr80 ${ }^{2.65}$, leu99 ${ }^{3.32}$, Ser103 ${ }^{3.36}$, Thr168 ${ }^{\mathrm{ECL} 2}$, 
A

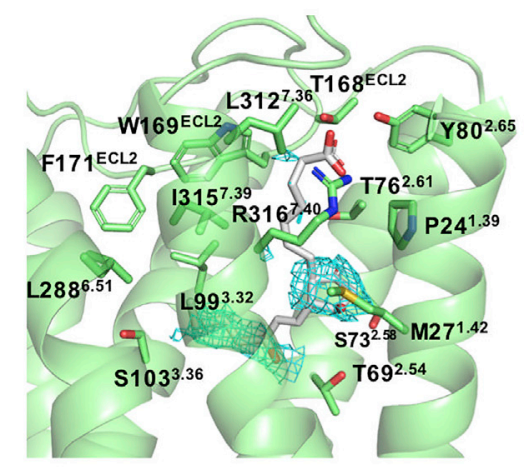

C
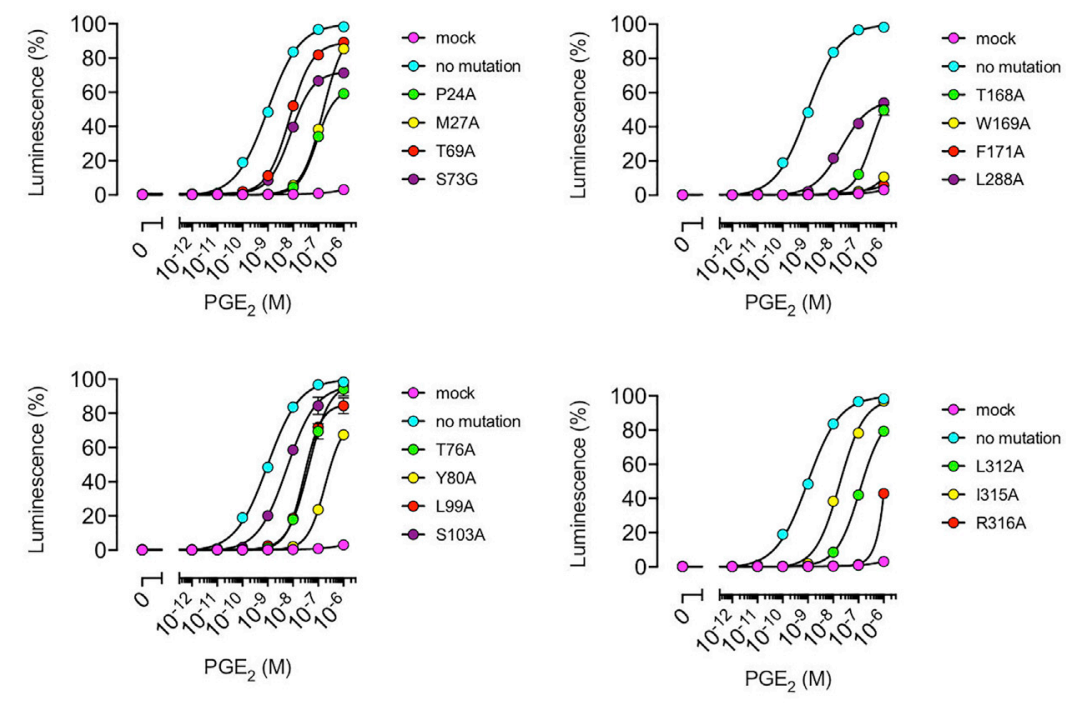

D

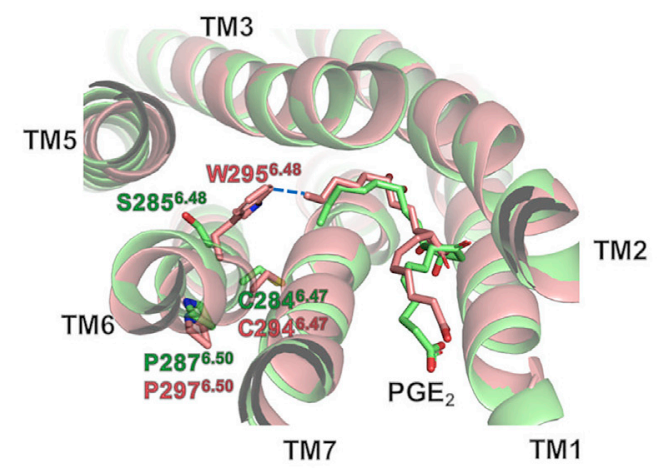

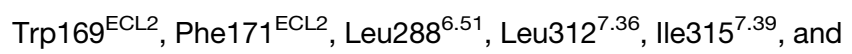
Arg316 ${ }^{7.40}$ decreased signal activity (Figure 3C; Table S1).

To compare the ligand-binding residues between EP4 and EP3, the crystal structure of EP3 bound to $\mathrm{PGE}_{2}$ (PDB: 6AK3) (Morimoto et al., 2019) was superimposed on the 3D model of the $P G E_{2}-E P 4-G s \beta_{1} \gamma_{2}-N b 35$ complex. The position of $P G E_{2}$ in EP4 was similar to that of EP3, and the conformation of the transmembrane helices of EP4 were similar to those of EP3 (Figure S5). These results indicated that the carboxyl group of $\mathrm{PGE}_{2}$ may form a salt bridge with $\mathrm{R} 316^{7.40}$ and hydrogen bonds

$\infty$ CellPress

Figure 3. Ligand-Binding Site of EP4 (A) Residues of EP4 interacting with $\mathrm{PGE}_{2}$. The side chains of EP4 and $P E_{2}$ are shown as sticks. Green, EP4; gray, $\mathrm{PGE}_{2}$. Cyan mesh indicates the density map around the $\mathrm{PGE}_{2}$ model.

(B) Comparison of the positions of $\mathrm{PGE}_{2}$ between EP4 (green) and EP3 (PDB: 6AK3) (light red). (C) Signaling analysis of EP4 site-directed mutants using a GloSensor cAMP assay. The experiments were performed in triplicates $(n=3)$ and the error bars indicate the standard error of the mean (SEM). (D) Comparison of the CWxP motif of EP4 (green) and EP3 (light red). See also Figures S3 and S5, and Table S1.

with $\mathrm{Tyr} 80^{2.65}$ and $\mathrm{Thr} 168^{\mathrm{ECL} 2}$, and that the hydrophobic $\omega$ chain of $\mathrm{PGE}_{2}$ was extended into the ligand-binding pocket, similar to that in EP3. The conformational similarity of EP3 and EP4 also indicated that $\mathrm{PGE}_{2}$ interacted with $\mathrm{TM} 1$ and TM7 and closed the gap after entering the orthosteric ligand-binding site via the gap.

On the other hand, the ligand-binding sites of EP3 and EP4 at the generally conserved CWxP motif differed (Figure 3D). In many class A GPCRs, the CWxP motif is called the transmission switch (Trzaskowski et al., 2012). Trp ${ }^{6.48}$ at the $\mathrm{CWxP}$ motif rotates when the ligand is bound to the receptor, triggering a large conformational change in TM6. Interestingly, EP4 contained Ser285 ${ }^{6.48}$ instead of the conserved $\operatorname{Trp}^{6.48}$ in the transmission switch. The side chain of serine is small, which distances it from the $\omega$ chain end of $\mathrm{PGE}_{2}$, whereas Trp ${ }^{6.48}$ of EP3 is in contact with the $\omega$ chain end of $P G E_{2}$. The distinct residues that triggered the outward shift of TM6 were not detected; hence, we speculated that the spatial occlusion of TM7 bound and shifted by $\mathrm{PGE}_{2}$ may cause a conformational change in TM6.

The EP4-Gs $\alpha$ Interface

In the 3D model of the EP4-Gs $\beta_{1} \gamma_{2}-\mathrm{Nb} 35$ complex, EP4 formed polar and nonpolar interactions with Gs, predominantly with the C-terminal $\alpha 5$ helix $(\alpha 5)$ of Gs. Gs binds with TM1, TM2, TM3, TM5, TM6, TM7, ICL1, and ICL2 of EP4. The loop between the $N$-terminal helix $(\alpha N)$, the first $\beta$ strand $(\beta 1)$, and the third and sixth $\beta$ strands ( $\beta 3$ and $\beta 6$ ) of Gs also interacted with EP4 (Figure $4 \mathrm{~A})$. In particular, His41 in the loop between $\alpha \mathrm{N}$ and $\beta 1$ formed a hydrogen bond with His $129^{34.55}$ of EP4. Phe219 in $\beta 3$ of Gs formed $\pi-\pi$ interactions with Tyr $125^{34.51}$ of EP4. Tyr358 in $\beta 6$ of Gs formed cation- $\pi$ interactions with Arg261 ${ }^{6.24}$ and hydrophobic interactions with Ile263 ${ }^{6.26}$. Tyr360 in $\beta 6$ of Gs formed $\pi-\pi$ interactions with Phe $217^{5.72}$, and cation- $\pi$ interactions with 


\section{$\infty$ CellPress}

A

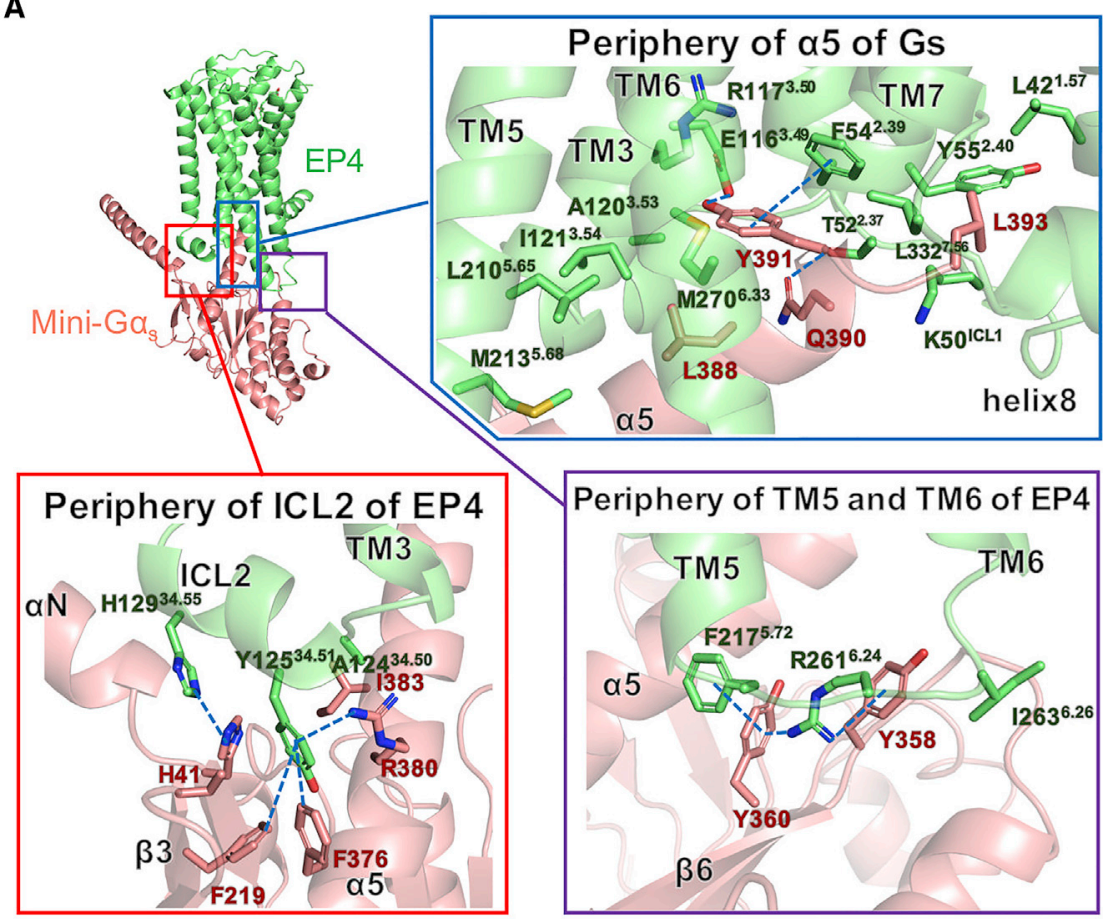

B

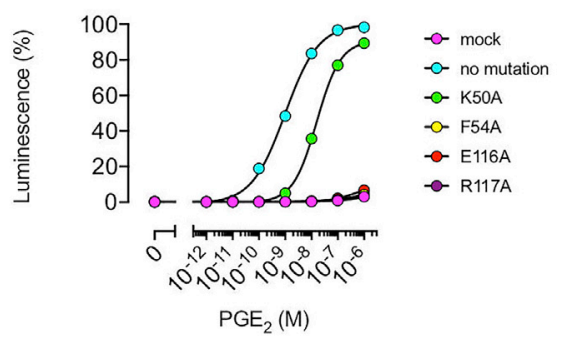

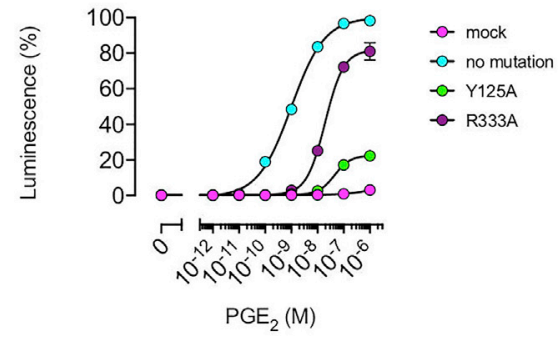

Figure 4. Interaction between EP4 and Gs (A) Binding residues of EP4 with Gs. Green, EP4; pink, mini-Gs. Blue dashed lines indicate the interactions between residues.

(B) Signaling analysis of EP4 site-directed mutants using the GloSensor cAMP assay. The experiments were performed in triplicates $(n=3)$ and the error bars indicate SEM.

See also Table S1.

complex (PDB: 6GDG), the outward shift of the TM6 of EP4 was smaller than that of the other receptors (Figure 5A). Instead, the intracellular end of TM7 opened outward, leading to the outward arrangement of helix 8 (Figure 5B). Regarding binding with Gs, the interaction sites of EP4 with the C-terminal helix of Gs are almost the same as those of $A_{2 A} R$, namely, TM3, ICL2, TM5, and TM6. However, the C-terminal hook of Gs did not interact with TM6. Instead, the hook was unwound and extended toward helix 8 (Figure 4A). Notably, EP4 had an extra interaction site at TM1, ICL1, and TM2 (Figure 5C). Phe54 ${ }^{2.39}$ on TM2 interacted with Tyr391 of Gs (Figure 5B). Phe54 $4^{2.39}$ is located not only near Tyr391 of Gs, but also near Tyr329 $9^{7.53}$. Tyr329 7.53 is a component of the N/DPxxY motif, which is one of the conserved motifs in class A GPCR. $\mathrm{Tyr}^{7.53}$ of the N/DPxxY motif is known to relocate to the center of the receptor when the receptor is activated (Trzaskowski et al., 2012). However, Tyr329 ${ }^{7.53}$ of EP4 is located outside $\mathrm{Tyr}^{7.53}$ of $\beta_{2} \mathrm{AR}$ or

Arg261 ${ }^{6.24}$. The $\alpha 5$ of Gs widely interacted with TM2, TM3, ICL2, TM5, and TM6 of EP4 via $\pi-\pi$ interactions (Phe376 with Tyr125 $5^{34.51}$, and Tyr391 with Phe54 ${ }^{2.39}$ ), cation- $\pi$ interactions (Arg380 with Tyr125 $5^{34.51}$ ), hydrogen bonds (Gln390 with Thr52 2.37 and Tyr391 with Glu116 ${ }^{3.49}$ ), and many other hydrophobic interactions. The C-terminal loop of Gs (corresponding to the C-terminal hook) interacted with TM1, TM2, and TM7 via hydrophobic interactions.

These interactions were also validated using the GloSensor cAMP assay (Figure 4B; Table S1). The mutation of the residues around the EP4-Gs interface, Lys50' ${ }^{\text {ICL1 }}$, Phe54 ${ }^{2.39}$, Glu116 ${ }^{3.49}$, Arg117 ${ }^{3.50}$, Tyr125 $5^{34.53}$, Leu274 ${ }^{6.37}$, and Arg333 8.47 , decreased signal activity. Lys $50^{\mathrm{ICL} 1}$ and $\operatorname{Arg} 117^{3.50}$ are relatively distant from Gs based on the EM structure, and the side chain of $\operatorname{Arg} 333^{8.47}$ was not modeled for the poor density on the map, although these residues were related to Gs signaling based on the signaling assay. Notably, critical residues for Gs signaling, Phe54 $4^{2.39}$, Glu116 ${ }^{3.49}$, and Arg117 $7^{3.50}$, are located near Tyr391 of Gs.

As described above, some structures of class A GPCR-Gs complexes had been determined. Compared with a representative of these structures, the cryo-EM structure of the $A_{2 A} R-G s$
$A_{2 A} R$. In addition, Trp32 $7^{7.51}$ is located at the outer surface of EP4. This large hydrophobic residue can interact with the hydrophobic residues of a neighbor helical pitch, such as Ile $330^{7.54}$, which bends the end of TM7 outside the receptor (Figure 5B). This conformational feature of TM7 maintains the space for the $\mathrm{C}$ terminus of $\mathrm{Gs}$ and allows the C-terminal hook of Gs to extend between TM1 and helix 8 . The C-terminal hook structures were conserved in the GPCR-G protein complex, irrespective of the class of GPCR and type of G protein. Therefore, this is the first case in which the C-terminal hook formed an extended state when the $\mathrm{G}$ protein binds to GPCR.

\section{DISCUSSION}

In this study, we aimed to reveal the activation mechanism of EP4 by determining an EM structure of the PGE $\mathrm{E}_{2}-\mathrm{EP} 4-\mathrm{Gs} \beta_{1} \gamma_{2^{-}}$ $\mathrm{Nb} 35$ complex. The cryo-EM structure of the $\mathrm{PGE}_{2}-\mathrm{EP} 4-$ Gs $\beta_{1} \gamma_{2}-\mathrm{Nb} 35$ complex revealed a unique binding mode and conformation of Gs. Two residues, $\mathrm{Phe}^{2.39}$ and $\operatorname{Trp}^{7.51}$, may characterize the conformation of the unique binding mode of prostanoid receptors. Compared with other class A GPCRs, the opening of TM6 of EP4 was smaller, and the C-terminal 
A

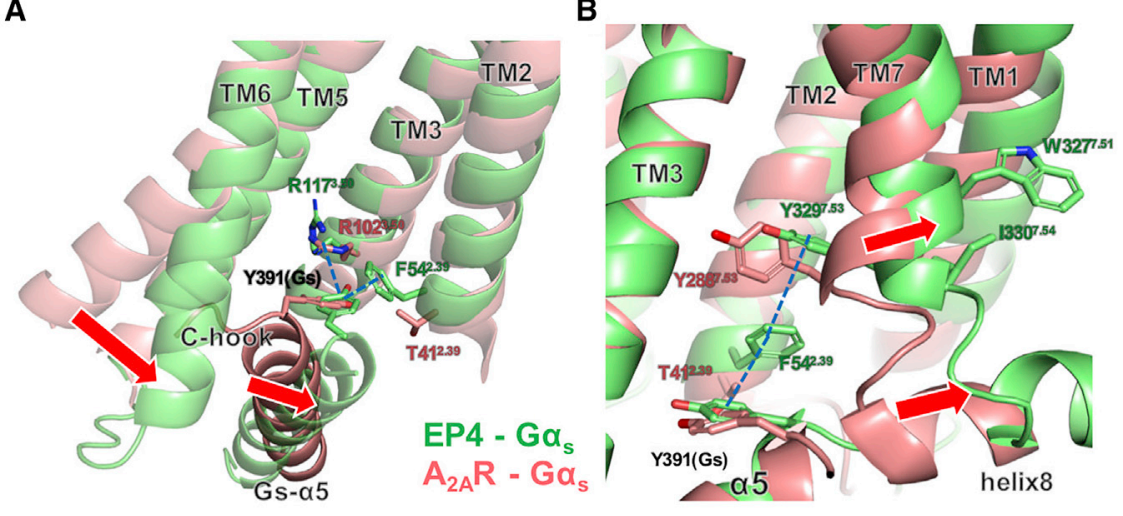

Figure 5. Structural Comparison of EP4 with Other Class A GPCR-Gs Complexes

(A) Structural comparison of the EP4-Gs complex and $A_{2 A}$-Gs complex (PDB: 6GDG) around $\alpha 5$ of $G s$ and TM6 of GPCR. Green, EP4-Gs complex; pink, $A_{2 A}-G$ complex. The structural differences are shown by red arrows.

(B) Structural comparison of the intracellular side of TM7 and the unique residues of EP4. Color code is as in (A).

(C) Schematic diagram of the secondary structures of EP4, $A_{2 A} R$, and mini-Gs. The boxes indicate $\alpha$ helices and arrows indicate $\beta$ strands. Lines between diagrams indicate the interactions between GPCR and Gs. Orange lines indicate the unique interaction site in the EP4-mini-Gs complex.

C

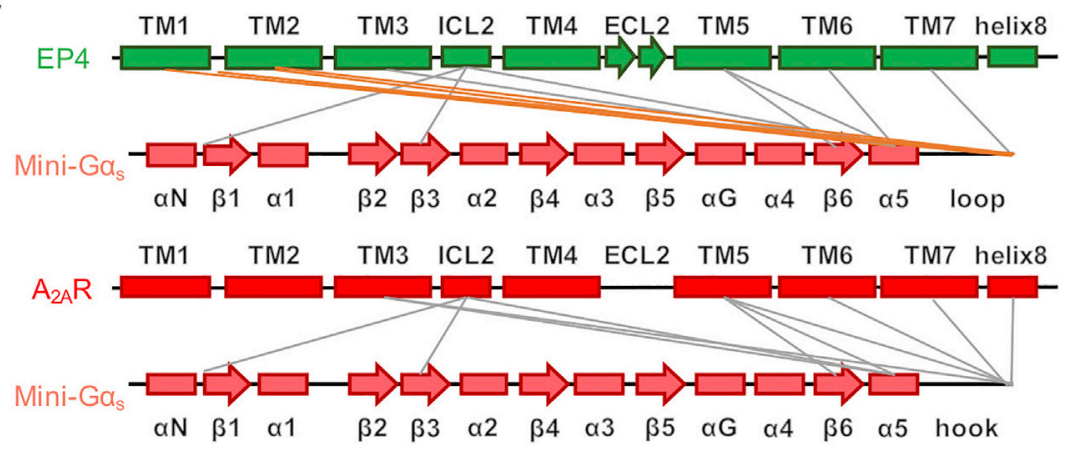

hook formed an extended state. Owing to the steric hindrance with TM6, the $\alpha 5$ helix of Gs was inserted toward the TM2 of EP4. Based on the structural analysis and results of the signaling assay, $\mathrm{Phe}^{2.39}$ Glu $^{3.49}$, and $\mathrm{Arg}^{3.50}$ are located near Tyr391 of Gs and are necessary for Gs signaling. Glu ${ }^{3.49}$ and Arg $^{3.50}$ are highly conserved in class A GPCRs. Arg ${ }^{3.50}$ is commonly involved in the interaction of class A GPCRs with Gs. Glu ${ }^{3.49}$ does not commonly interact with Gs; however, the difference in the $\alpha 5$ helix position allows interaction between $\mathrm{Glu}^{3.49}$ and Tyr391 of Gs.

Furthermore, there are, besides prostanoid receptors, some class A GPCRs that have an aromatic side chain at residue 2.39. The relaxin receptors (RXFP1 and 2) and ADP receptors $\left(\mathrm{P}_{2} \mathrm{Y}_{12}, \mathrm{P}_{2} \mathrm{Y}_{13}\right.$, and $\mathrm{P}_{2 Y_{14}}$ ) also have $\mathrm{Phe}$, His, or Tyr at residue 2.39. In addition, Tyr391 of Gs corresponds to Cys in Gi/Go, Tyr in Gq, and Ile in G12 (Nehmé et al., 2017); hence, at least Gi/Go and Gq may interact with $\mathrm{Phe}^{2.39}$ via S- $\pi$ or $\pi-\pi$ interactions. Taken together, these receptors may also interact with $G$ protein using a residue at the 2.39 position. $P h e^{2.39}$ also interacts with Tyr3297.53 in the N/DPxxY motif and prevents TM7 from shifting inward in the receptor.

In addition, $\operatorname{Trp}^{7.51}$ also opens TM7 outward on the intracellular side. $\operatorname{Trp}^{7.51}$ is also conserved in prostanoid receptors. Besides prostanoid receptors, vasopressin receptors $\left(\mathrm{V}_{1 \mathrm{~A}}\right.$ and $\left.\mathrm{V}_{1 \mathrm{~B}}\right)$ are the other class A GPCRs that have tryptophan at residue 7.51. The C-terminal hook of the $\mathrm{G}$ protein coupled to these receptors may be extended as well as coupled to EP4.

This suggests that GPCRs of the same class have different critical residues for binding to $G$ protein, and that solving the structure of individual GPCR-G protein complexes may be necessary to reveal the activation mechanism of each GPCR.
In contrast, based on the sequence conservation and structural similarity of the active state structure of EP3, these structural features appear to be common in the prostanoid receptor family. Our findings should be applicable to the prostanoid receptors and some GPCRs that have the same unique residues, and they must strongly support studies regarding the activation mechanism of these receptors.

\section{STAR $\star$ METHODS}

Detailed methods are provided in the online version of this paper and include the following:

- KEY RESOURCES TABLE

- RESOURCE AVAILABILITY

○ Lead Contact

O Materials Availability

O Data and Code Availability

- EXPERIMENTAL MODEL AND SUBJECT DETAILS

O Microbes

C Cell Lines

- METHOD DETAILS

O Construction, Expression, and Purification of EP4

O Construction, Expression, and Purification of Mini-Gs399

O Construction, Expression, and Purification of $\mathrm{G} \beta_{1}$ and $\mathrm{G}_{\gamma_{2}}$

O Construction, Expression, and Purification of Nb35

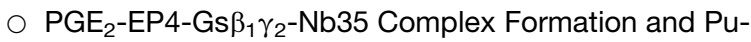
rification 


\author{
O Cryo-EM Single Particle Analysis of the PGE 2 -EP4- \\ Gs $\beta_{1} \gamma_{2}-\mathrm{Nb} 35$ Complex \\ $\bigcirc$ Model Building and Refinement \\ - GloSensor cAMP Assay \\ - QUANTIFICATION AND STATISTICAL ANALYSIS
}

\section{SUPPLEMENTAL INFORMATION}

Supplemental Information can be found online at https://doi.org/10.1016/j.str. 2020.11.007.

\section{ACKNOWLEDGMENTS}

This study was supported by JSPS KAKENHI grant no. JP19J12880 (to S.N.), AMED Core Research for Evolutional Science and Technology (CREST) under grant no. JP20gm0910007 (to T.K.), AMED Science and Technology Platform Program for Advanced Biological Medicine under grant no. JP20am0401020 (to T.K.), AMED Research on Development of New Drugs under grant no. JP20ak0101103 (to T.K., M.Y., H.S., and S.I.), Takeda Science Foundation (to T.K.), the Naito Foundation (to T.K.), Koyanagi Foundation (to T.K.), Private University Research Branding Project (to T.K.), AMED Basis for Supporting Innovative Drug Discovery and Life Science Research (BINDS) under grant no. JP20am0101079 (to S.I.), an AMED Research Program on Emerging and Re-emerging Infectious Disease grants under grant no. $19 \mathrm{fk} 0108113$ and 20fk0108270h0001 (to T.N.), and JSPS Core-to-Core Program A (to T.N.). This work was also supported in part by the RIKEN Dynamic Structural Biology project (to M.Y. and H.S.). We thank Drs. A. Tsutsumi, M. Kikkawa (Cryo-EM facility in the University of Tokyo, Tokyo, Japan) for their help in cryo-EM data collection. The cryo-EM data collection of this work was partially supported by AMED BINDS under grant no. JP19am0101115 (support no. 2365). DNA sequencing analysis was performed at the Medical Research Support Center, Graduate School of Medicine, Kyoto University. The manuscript was proofread by Editage (https://www.editage.jp/).

\section{AUTHOR CONTRIBUTIONS}

S.N., R.S., M.Y., T.N., S.I., H.S., and T.K. designed the project. S.N., R.S., and K.M. constructed the expression vector. S.N. expressed and purified the sample under the supervision of R.S. and N.N., and then Y.F., K.T.K., and H.S. prepared the sample grid, collected the cryo-EM images, and processed the EM data. S.N. built the 3D model. S.N. and K.M. designed and performed the GloSensor CAMP assay and analyzed the data. S.N. and Y.F. analyzed the data and compiled the figures for the manuscript. S.N. and H.S. wrote the manuscript. All authors discussed the results and commented on the manuscript.

\section{DECLARATION OF INTERESTS}

The authors declare no competing interests.

Received: October 7, 2020

Revised: October 27, 2020

Accepted: November 6, 2020

Published: December 1, 2020

\section{REFERENCES}

Adams, P.D., Afonine, P.V., Bunkóczi, G., Chen, V.B., Davis, I.W., Echols, N., Headd, J.J., Hung, L.W., Kapral, G.J., Grosse-Kunstleve, R.W., et al. (2010). PHENIX: a comprehensive Python-based system for macromolecular structure solution. Acta Crystallogr. Sect. D Biol. Crystallogr. 66, 213-221.

Afonine, P.V., Poon, B.K., Read, R.J., Sobolev, O.V., Terwilliger, T.C., Urzhumtsev, A., and Adams, P.D. (2018). Real-space refinement in PHENIX for cryo-EM and crystallography. Acta Crystallogr. Sect. D Struct. Biol. 74, 531-544.

Audet, M., and Stevens, R.C. (2019). Emerging structural biology of lipid G protein-coupled receptors. Protein Sci. 28, 292-304.
Audet, M., White, K.L., Breton, B., Zarzycka, B., Han, G.W., Lu, Y., Gati, C., Batyuk, A., Popov, P., Velasquez, J., et al. (2019). Crystal structure of misoprostol bound to the labor inducer prostaglandin $E_{2}$ receptor. Nat. Chem. Biol. 15, 11-17.

Bao, X., Albu, D., Huang, K.-C., Wu, J., Twine, N., Nomoto, K., and WoodallJappe, M. (2015). Combination of EP4 antagonist and checkpoint inhibitors promotes anti-tumor effector $\mathrm{T}$ cells in preclinical tumor models. J. Immunother. Cancer 3, P350.

Bastien, L., Sawyer, N., Grygorczyk, R., Kathleen, M.M., and Adam, M. (1994). Cloning, functional expression, and characterization of the human prostaglandin E, receptor EP2 subtype. J. Biol. Chem. 269, 11873-11877.

Cao, C., Tan, Q., Xu, C., He, L., Yang, L., Zhou, Y., Zhou, Y., Qiao, A., Lu, M., Yi, C., et al. (2018). Structural basis for signal recognition and transduction by platelet-activating-factor receptor. Nat. Struct. Mol. Biol. 25, 488-495.

Carpenter, B., and Tate, C.G. (2016). Engineering a minimal G protein to facilitate crystallisation of $G$ protein-coupled receptors in their active conformation. Protein Eng. Des. Sel. 29, 583-593.

Chrencik, J.E., Roth, C.B., Terakado, M., Kurata, H., Omi, R., Kihara, Y., Warshaviak, D., Nakade, S., Asmar-Rovira, G., Mileni, M., et al. (2015). Crystal structure of antagonist bound human lysophosphatidic acid receptor 1. Cell 161, 1633-1643.

Davis, I.W., Leaver-Fay, A., Chen, V.B., Block, J.N., Kapral, G.J., Wang, X., Murray, L.W., Arendall, W.B., Snoeyink, J., Richardson, J.S., et al. (2007). MolProbity: all-atom contacts and structure validation for proteins and nucleic acids. Nucleic Acids Res. 35, 375-383.

Emsley, P., and Cowtan, K. (2004). Coot: model-building tools for molecular graphics. Acta Crystallogr. Sect. D Biol. Crystallogr. 60, 2126-2132.

Fan, H., Chen, S., Yuan, X., Han, S., Zhang, H., Xia, W., Xu, Y., Zhao, Q., and $\mathrm{Wu}$, B. (2019). Structural basis for ligand recognition of the human thromboxane $\mathrm{A}_{2}$ receptor. Nat. Chem. Biol. 15, 27-33.

Fujino, H., and Regan, J.W. (2006). EP 4 prostanoid receptor coupling to a pertussis toxin-sensitive inhibitory G protein. Mol. Pharmacol. 69, 5-10.

García-Nafría, J., Lee, Y., Bai, X., Carpenter, B., and Tate, C.G. (2018). Cryo$E M$ structure of the adenosine $A_{2 A}$ receptor coupled to an engineered heterotrimeric $G$ protein. eLife 7, e35946.

Gilman, A.G. (1987). G proteins: transducers of receptor-generated signals. Annu. Rev. Biochem. 56, 615-649.

Goddard, T.D., Huang, C.C., Meng, E.C., Pettersen, E.F., Couch, G.S., Morris, J.H., and Ferrin, T.E. (2018). UCSF ChimeraX: meeting modern challenges in visualization and analysis. Protein Sci. 27, 14-25.

Guan, Y., Stillman, B.A., Zhang, Y., Schneider, A., Saito, O., Davis, L.S., Redha, R., Breyer, R.M., and Breyer, M.D. (1996). Cloning and expression of the rabbit prostaglandin EP4 receptor. Am. J. Physiol. 270, F485-F493.

Gusach, A., Luginina, A., Marin, E., Brouillette, R.L., Besserer-Offroy, É., Longpré, J.M., Ishchenko, A., Popov, P., Patel, N., Fujimoto, T., et al. (2019). Structural basis of ligand selectivity and disease mutations in cysteinyl leukotriene receptors. Nat. Commun. 10, 5573.

Hanson, M.A., Roth, C.B., Jo, E., Griffith, M.T., Scott, F.L., Reinhart, G., Desale, H., Clemons, B., Cahalan, S.M., Schuerer, S.C., et al. (2012). Crystal structure of a lipid G protein-coupled receptor. Science 335, 851-855.

Hirata, T., and Narumiya, S. (2011). Prostanoid receptors. Chem. Rev. 111, 6209-6230.

Honda, A., Sugimoto, Y., Namba, T., Watabe, A., Irie, A., Negishi, M., Narumiya, S., and Ichikawa, A. (1993). Cloning and expression of a cDNA for mouse prostaglandin E receptor EP2 subtype. J. Biol. Chem. 268, 7759-7762. Hori, T., Okuno, T., Hirata, K., Yamashita, K., Kawano, Y., Yamamoto, M., Hato, M., Nakamura, M., Shimizu, T., Yokomizo, T., et al. (2018). $\mathrm{Na}^{+}-$ mimicking ligands stabilize the inactive state of leukotriene $B_{4}$ receptor BLT1. Nat. Chem. Biol. 14, 262-269.

Hua, T., Vemuri, K., Pu, M., Qu, L., Han, G.W., Wu, Y., Zhao, S., Shui, W., Li, S., Korde, A., et al. (2016). Crystal structure of the human cannabinoid receptor $\mathrm{CB}_{1}$. Cell 167, 750-762.e14. 


\section{Structure} Article

Hua, T., Vemuri, K., Nikas, S.P., Laprairie, R.B., Wu, Y., Qu, L., Pu, M., Korde, A., Jiang, S., Ho, J.H., et al. (2017). Crystal structures of agonist-bound human cannabinoid receptor $\mathrm{CB}_{1}$. Nature 547, 468-471.

Hua, T., Li, X., Wu, L., Iliopoulos-Tsoutsouvas, C., Wang, Y., Wu, M., Shen, L., Johnston, C.A., Nikas, S.P., Song, F., et al. (2020). Activation and signaling mechanism revealed by cannabinoid receptor-Gi complex structures. Cell 180, 655-665.e18.

Inoue, A., Ishiguro, J., Kitamura, H., Arima, N., Okutani, M., Shuto, A., Higashiyama, S., Ohwada, T., Arai, H., Makide, K., et al. (2012). TGF $\alpha$ shedding assay: an accurate and versatile method for detecting GPCR activation. Nat. Methods 9, 1021-2029.

Inoue, A., Raimondi, F., Kadji, F.M.N., Singh, G., Kishi, T., Uwamizu, A., Ono, Y., Shinjo, Y., Ishida, S., Arang, N., et al. (2019). Illuminating G-proteincoupling selectivity of GPCRs. Cell 177, 1933-1947.e25.

Kumar, K.K., Shalev-Benami, M., Robertson, M.J., Hu, H., Banister, S.D., Hollingsworth, S.A., Latorraca, N.R., Kato, H.E., Hilger, D., Maeda, S., et al. (2019). Structure of a signaling cannabinoid receptor 1-G protein complex. Cell 176, 448-458.e12.

Lin, X., Li, M., Wang, N., Wu, Y., Luo, Z., Guo, S., Han, G.W., Li, S., Yue, Y., Wei, $X$., et al. (2020). Structural basis of ligand recognition and self-activation of orphan GPR52. Nature 579, 152-157.

Luginina, A., Gusach, A., Marin, E., Mishin, A., Brouillette, R., Popov, P., Shiriaeva, A., Besserer-Offroy, É., Longpré, J.M., Lyapina, E., et al. (2019). Structure-based mechanism of cysteinyl leukotriene receptor inhibition by antiasthmatic drugs. Sci. Adv. 5, 2518.

Morimoto, K., Suno, R., Hotta, Y., Yamashita, K., Hirata, K., Yamamoto, M., Narumiya, S., Iwata, S., and Kobayashi, T. (2019). Crystal structure of the endogenous agonist-bound prostanoid receptor EP3. Nat. Chem. Biol. 15, 8-10.

Nehmé, R., Carpenter, B., Singhal, A., Strege, A., Edwards, P.C., White, C.F., Du, H., Grisshammer, R., and Tate, C.G. (2017). Mini-G proteins: novel tools for studying GPCRs in their active conformation. PLoS One 12, e0175642.

Pettersen, E.F., Goddard, T.D., Huang, C.C., Couch, G.S., Greenblatt, D.M., Meng, E.C., and Ferrin, T.E. (2004). UCSF Chimera-a visualization system for exploratory research and analysis. J. Comput. Chem. 25, 1605-1612.

Rasmussen, S.G.F., Devree, B.T., Zou, Y., Kruse, A.C., Chung, K.Y., Kobilka, T.S., Thian, F.S., Chae, P.S., Pardon, E., Calinski, D., et al. (2011). Crystal structure of the $\beta_{2}$ adrenergic receptor-Gs protein complex. Nature 477 , 549-555.

Rausch-Derra, L., Huebner, M., Wofford, J., and Rhodes, L. (2016). A prospective, randomized, masked, placebo-controlled multisite clinical study of grapiprant, an EP4 prostaglandin receptor antagonist (PRA), in dogs with osteoarthritis. J. Vet. Intern. Med. 30, 756-763.

Rohou, A., and Grigorieff, N. (2015). CTFFIND4: fast and accurate defocus estimation from electron micrographs. J. Struct. Biol. 192, 216-221.

Sando, T., Usui, T., Tanaka, I., Mori, K., Sasaki, Y., Fukuda, Y., Namba, T., Sugimoto, Y., Ichikawa, A., Narumiya, S., et al. (1994). Molecular cloning and expression of rat prostaglandin E receptor EP2 subtype. Biochem. Biophys. Res. Commun. 200, 1329-1333.
Schorb, M., Haberbosch, I., Hagen, W.J.H., Schwab, Y., and Mastronarde, D.N. (2019). Software tools for automated transmission electron microscopy. Nat. Methods 16, 471-477.

Shao, Z., Yin, J., Chapman, K., Grzemska, M., Clark, L., Wang, J., and Rosenbaum, D.M. (2016). High-resolution crystal structure of the human CB1 cannabinoid receptor. Nature 540, 602-606.

Su, M., Zhu, L., Zhang, Y., Paknejad, N., Dey, R., Huang, J., Lee, M.-Y., Williams, D., Jordan, K.D., Eng, E.T., et al. (2020). Structural basis of the activation of heterotrimeric Gs-protein by isoproterenol-bound $\beta_{1}$-adrenergic receptor. Mol. Cell. 80, 59-71.e4.

Taniguchi, R., Inoue, A., Sayama, M., Uwamizu, A., Yamashita, K., Hirata, K., Yoshida, M., Tanaka, Y., Kato, H.E., Nakada-Nakura, Y., et al. (2017). Structural insights into ligand recognition by the lysophosphatidic acid receptor $\mathrm{LPA}_{6}$. Nature $548,356-360$.

Toyoda, Y., Morimoto, K., Suno, R., Horita, S., Yamashita, K., Hirata, K. Sekiguchi, Y., Yasuda, S., Shiroishi, M., Shimizu, T., et al. (2019). Ligand binding to human prostaglandin E receptor EP4 at the lipid-bilayer interface. Nat. Chem. Biol. 15, 18-26.

Trzaskowski, B., Latek, D., Yuan, S., Ghoshdastider, U., Debinski, A., and Filipek, S. (2012). Action of molecular switches in GPCRs-theoretical and experimental studies. Curr. Med. Chem. 19, 1090-1109.

Wang, L., Yao, D., Deepak, R.N.V.K., Liu, H., Xiao, Q., Fan, H., Gong, W., Wei, Z., and Zhang, C. (2018). Structures of the human $\mathrm{PGD}_{2}$ receptor CRTH2 reveal novel mechanisms for ligand recognition. Mol. Cell. 72, 48-59.

Ward, C.L., Jamieson, V., Nabata, T., Sharpe, J., Dozono, K., Suto, F., Hashimoto, Y., and Gussak, I. (2016). First clinical experience with ONO4232: a randomized, double-blind, placebo-controlled healthy volunteer study of a novel lusitropic agent for acutely decompensated heart failure. Clin. Ther. 38, 1109-1121.

Watanabe, Y., Murata, T., Amakawa, M., Miyake, Y., Handa, T., Konishi, K., Matsumura, Y., Tanaka, T., and Takeuchi, K. (2015). KAG-308, a newly-identified EP4-selective agonist shows efficacy for treating ulcerative colitis and can bring about lower risk of colorectal carcinogenesis by oral administration. Eur. J. Pharmacol. 754, 179-189.

Yokoyama, U., Iwatsubo, K., Umemura, M., Fujita, T., and Ishikawa, Y. (2013). The prostanoid EP4 receptor and its signaling pathway. Pharmacol. Rev. 65 , 1010-1052.

Yoshida, K., Oida, H., Kobayashi, T., Maruyama, T., Tanaka, M., Katayama, T., Yamaguchi, K., Segi, E., Tsuboyama, T., Matsushita, M., et al. (2002). Stimulation of bone formation and prevention of bone loss by prostaglandin E EP4 receptor activation. Proc. Natl. Acad. Sci. U S A 99, 4580-4585.

Zhang, Y., Yang, F., Ling, S., Lv, P., Zhou, Y., Fang, W., Sun, W., Zhang, L., Shi, P., and Tian, C. (2020). Single-particle cryo-EM structural studies of the $\beta_{2} A R-$ Gs complex bound with a full agonist formoterol. Cell Discov. 6, 45.

Zivanov, J., Nakane, T., Forsberg, B.O., Kimanius, D., Hagen, W.J.H., Lindahl, E., and Scheres, S.H.W. (2018). New tools for automated high-resolution cryoEM structure determination in RELION-3. Elife 7, e42166. 


\section{STAR $\star$ METHODS}

\section{KEY RESOURCES TABLE}

\begin{tabular}{|c|c|c|}
\hline REAGENT or RESOURCE & SOURCE & IDENTIFIER \\
\hline \multicolumn{3}{|l|}{ Bacterial and Virus Strains } \\
\hline $\begin{array}{l}\text { Escherichia coli BL21-CodonPlus } \\
\text { (DE3)-RIPL cells }\end{array}$ & Agilent Technologies & Cat\# 230280 \\
\hline pFastBac baculovirus system & Invitrogen & Cat\# 10359-016 \\
\hline $\begin{array}{l}\text { BestBac } 2.0, v \text {-cath/chiA deleted } \\
\text { baculovirus cotransfection system }\end{array}$ & Expression Systems & Cat\# 91-002 \\
\hline Brevibacillus competent cells & Takara Bio & Cat\# HB116 \\
\hline \multicolumn{3}{|c|}{ Chemicals, Peptides, and Recombinant Proteins } \\
\hline Protease inhibitor cocktail & Nacalai Tesque & Cat\# 25955-11 \\
\hline $\begin{array}{l}\text { DDM (n-dodecyl-b-D- } \\
\text { maltopyranoside), } \\
\text { Sol-grade }\end{array}$ & Anatrace & Cat\# D310S \\
\hline Cholesterol hemi-succinate & Sigma & Cat\# C6512 \\
\hline Colic acid sodium salt & Nacalai Tesque & Cat\# 08805-56 \\
\hline lodoacetamide & $\begin{array}{l}\text { FujiFilm Wako Pure Chemical } \\
\text { Corporation }\end{array}$ & Cat\# 093-02892 \\
\hline $\begin{array}{l}\text { Lauryl maltose neopentyl } \\
\text { glycol (MNG) }\end{array}$ & Anatrace & Cat\# NG310 25 GM \\
\hline GDN & Anatrace & Cat\# GDN10125 GM \\
\hline ONO-AE3-208 & Cayman & Cat\# 14522 \\
\hline $\mathrm{PGE}_{2}$ & Cayman & Cat\# 14010 \\
\hline PF-04418948 & Funakoshi & Cat\# 15016 \\
\hline Apyrase & NEB & Cat\# M0398L \\
\hline D-luciferin & $\begin{array}{l}\text { FujiFilm Wako Pure Chemical } \\
\text { Corporation }\end{array}$ & Cat\# 127-03941 \\
\hline \multicolumn{3}{|l|}{ Critical Commercial Assays } \\
\hline GloSensor $^{\mathrm{TM}}$ cAMP assay & Promega & Cat\# E2301 \\
\hline \multicolumn{3}{|l|}{ Deposited data } \\
\hline $\begin{array}{l}\mathrm{PGE}_{2}-\mathrm{EP} 4-\mathrm{Gs} \beta_{1} \gamma_{2}-\mathrm{Nb} 35 \\
\text { complex map }\end{array}$ & This paper & EMDB EMD-30608 \\
\hline $\begin{array}{l}\text { PGE }{ }_{2} \text {-EP4-Gs } \beta_{1} \gamma_{2}-\mathrm{Nb} 35 \\
\text { complex model }\end{array}$ & This paper & PDB 7D7M \\
\hline Crystal structure of EP4 & (Toyoda et al., 2019) & PDB 5YWY \\
\hline Crystal structure of EP3 & (Morimoto et al., 2019) & PDB 6AK3 \\
\hline Cryo-EM structure of $A_{2 A} R$ & (García-Nafría et al., 2018) & PDB 6GDG \\
\hline \multicolumn{3}{|l|}{ Experimental Models: Cell Lines } \\
\hline $\begin{array}{l}\text { Spodoptera frugiperda } 9 \text { (Sf9) } \\
\text { insect cells }\end{array}$ & Thermo Fisher Scientific & Cat\# 11496-015 \\
\hline $\begin{array}{l}\text { Human embryonic kidney } 293 \\
\text { (HEK293) cells }\end{array}$ & (Inoue et al., 2012) & N/A \\
\hline \multicolumn{3}{|l|}{ Recombinant DNA } \\
\hline pFastBac1-EP4-GFP & This paper & N/A \\
\hline pET21a-mini-Gs399 & This paper & N/A \\
\hline $\mathrm{pVL} 1393-\mathrm{G} \beta_{1}-\mathrm{G}_{\gamma_{2}}$ & This paper & N/A \\
\hline pNY326-Nb35 & This paper & N/A \\
\hline pcDNA3.1-EP4 & This paper & N/A \\
\hline pGloSensor-22F cAMP Plasmid & Promega & Cat\# E2301 \\
\hline
\end{tabular}




\begin{tabular}{|c|c|c|}
\hline \multicolumn{3}{|l|}{ Continued } \\
\hline REAGENT or RESOURCE & SOURCE & IDENTIFIER \\
\hline \multicolumn{3}{|l|}{ Software and Algorithms } \\
\hline SerialEM & (Schorb et al., 2019) & $\begin{array}{l}\text { https://bio3d.colorado.edu/ } \\
\text { SerialEM/ }\end{array}$ \\
\hline RELION 3.0 .8 and 3.1 beta & (Zivanov et al., 2018) & $\begin{array}{l}\text { https://www3.mrc-Imb.cam.ac.uk/ } \\
\text { relion/index.php/Main_Page }\end{array}$ \\
\hline CTFFIND4 & (Rohou and Grigorieff, 2015) & $\begin{array}{l}\text { https://grigoriefflab.umassmed. } \\
\text { edu/ctffind4 }\end{array}$ \\
\hline Chimera version 1.14 & (Pettersen et al., 2004) & https://www.cgl.ucsf.edu/chimera/ \\
\hline $\begin{array}{l}\text { ChimeraX version: } \\
\text { 1.0rc202005180441 (2020-05-18) }\end{array}$ & (Goddard et al., 2018) & $\begin{array}{l}\text { https://www.cgl.ucsf.edu/ } \\
\text { chimerax/ }\end{array}$ \\
\hline COOT v0.8.9.2 & (Emsley and Cowtan, 2004) & $\begin{array}{l}\text { https://strucbio.biologie. } \\
\text { unikonstanz.de/ccp4wiki/index. } \\
\text { php/Coot }\end{array}$ \\
\hline Phenix v1.18-3845-000 & (Adams et al., 2010) & https://www.phenix-online.org/ \\
\hline phenix.real_space_refine & (Afonine et al., 2018) & https://www.phenix-online.org/ \\
\hline MolProbity & (Davis et al., 2007) & https://www.phenix-online.org/ \\
\hline Pymol & Schrödinger & http://www.pymol.org \\
\hline Prism 8 & GraphPad Software & $\begin{array}{l}\text { https://www.graphpad.com/ } \\
\text { scientific-software/prism/ }\end{array}$ \\
\hline \multicolumn{3}{|l|}{ Other } \\
\hline Ni-NTA resin & Qiagen & Cat\# 30250 \\
\hline FLAG M1 affinity resin & Sigma & Cat\# A4596-25ML \\
\hline $\begin{array}{l}\text { Amicon Ultra- } 15 \text { centrifugal filter } \\
\text { units } 50,000 \mathrm{MWCO}\end{array}$ & Millipore & Cat\# UFC905096 \\
\hline $\begin{array}{l}\text { Amicon Ultra- } 15 \text { centrifugal filter } \\
\text { units } 10,000 \text { MWCO }\end{array}$ & Millipore & Cat\# UFC901096 \\
\hline $\begin{array}{l}\text { Amicon Ultra- } 4 \text { centrifugal filter units } \\
50,000 \mathrm{MWCO}\end{array}$ & Millipore & Cat\# UFC805096 \\
\hline Superdex 200 Increase 10/300 GL & GE Healthcare & Cat\# 28990944 \\
\hline PSFM-J1 medium & $\begin{array}{l}\text { FujiFilm Wako Pure Chemical } \\
\text { Corporation }\end{array}$ & Cat\# 160-25851 \\
\hline Fetal bovine serum & Sigma & Cat\# 172012-500ML \\
\hline $\begin{array}{l}\text { Dulbecco's modified Eagle's } \\
\text { medium }\end{array}$ & Sigma & Cat\# D6046-500ML \\
\hline $\begin{array}{l}\text { HBSS, calcium, magnesium, no } \\
\text { phenol red }\end{array}$ & Gibco & Cat\# 14025076 \\
\hline $\begin{array}{l}\text { Quantifoil grid of R0.6/R1.0 } 300 \\
\text { mesh copper }\end{array}$ & Quantifoil & Cat\# Q325CR-06 \\
\hline
\end{tabular}

\section{RESOURCE AVAILABILITY}

\section{Lead Contact}

Further information and requests for resources and reagents should be directed to and will be fulfilled by the lead contact, Takuya Kobayashi (kobayatk@hirakata.kmu.ac.jp)

\section{Materials Availability}

This study did not generate new unique reagents.

\section{Data and Code Availability}

The cryo-EM reconstructions generated in this study have been deposited into the Electron Microscopy Data Bank with accession numbers EMDB: EMD-30608. The 3D models reported in this paper have been deposited in the Protein Data Bank with accession code PDB: 7D7M. All other data are available from the corresponding authors on reasonable request. 


\section{$\infty$ CellPress}

\section{Structure Article}

\section{EXPERIMENTAL MODEL AND SUBJECT DETAILS}

\section{Microbes}

Escherichia coli BL21-CodonPlus (DE3)-RIPL cells (Agilent Technologies) were cultivated in terrific broth (TB) supplemented with $100 \mathrm{mg} / \mathrm{L}$ ampicillin at $37^{\circ} \mathrm{C}$. Brevibacillus competent cells were cultivated in $2 \mathrm{SY}$ medium supplemented with $50 \mathrm{mg} / \mathrm{L}$ neomycin at $30^{\circ} \mathrm{C}$. Spodoptera frugiperda 9 (Sf9) insect cells were cultured in PSFM-J1 medium (Wako) supplemented with $2 \%$ fetal bovine serum (FBS) (Sigma), 50 units $/ \mathrm{mL}$ penicillin, $50 \mu \mathrm{g} / \mathrm{mL}$ streptomycin (Wako), and $0.5 \mu \mathrm{g} / \mathrm{mL}$ amphotericin $\mathrm{B}$ at $27^{\circ} \mathrm{C}$.

\section{Cell Lines}

Human embryonic kidney 293 (HEK293) cells were grown in Dulbecco's modified Eagle's medium supplemented with 10\% FBS (Sigma-Aldrich), 100 units $/ \mathrm{mL}$ penicillin, and $100 \mu \mathrm{g} / \mathrm{mL}$ streptomycin (Wako) at $37^{\circ} \mathrm{C}$ in a $5 \% \mathrm{CO}_{2}$ incubator.

\section{METHOD DETAILS}

\section{Construction, Expression, and Purification of EP4}

The sequence of human EP4 was inserted into the Sf9 expression vector, pFastBac1 (Thermo Fisher Scientific). The N-terminal residues (residues 1-3), C-terminal residues (residues 347-488), and intracellular loop 3 (residues 218-259) were deleted, and N-linked glycosylation sites (Asn7 and Asn177) were mutated to glutamine. In addition, the hemagglutinin signal sequence, FLAG tag, and 3C protease cleavage site were added to the $\mathrm{N}$-terminus, and the $3 \mathrm{C}$ cleavage site and GFP sequence were added to the $\mathrm{C}$-terminus. This plasmid was named pFastBac1-EP4-GFP.

Recombinant baculovirus was obtained using the Bac-to-Bac baculovirus expression system (Invitrogen). Sf9 insect cells were cultured in a PSFM-J1 medium (Wako) supplemented with 2\% FBS (Sigma-Aldrich), 50 units/mL penicillin, $50 \mu \mathrm{g} / \mathrm{mL}$ streptomycin, and $0.5 \mu \mathrm{g} / \mathrm{mL}$ amphotericin B. After the cell density reached $3.5 \times 10^{6}$, the Sf9 cells were infected with the baculovirus at a multiplicity of infection (M.O.I.) of 2 and cultivated at $27^{\circ} \mathrm{C}$ for 3 days. The cells were harvested via centrifugation at $7,000 \times g$ for 10 min and re-harvested via centrifugation at $8,000 \times g$ for 10 min after washing with phosphate-buffered saline (PBS) (-). The cells were suspended in $80 \%$ glycerol and stored at $-80^{\circ} \mathrm{C}$.

The cells were lysed in buffer A (10 mM HEPES [pH 7.5], $20 \mathrm{mM} \mathrm{KCl,} 10 \mathrm{mM} \mathrm{MgCl}_{2}, 1 \mu \mathrm{M}$ ONO-AE3-208, and protease inhibitor cocktail). The suspension was homogenized with a dounce homogenizer and ultracentrifuged at $140,000 \times g$ for 30 min at $4{ }^{\circ} \mathrm{C}$. The precipitate was suspended in buffer B (10 mM HEPES [pH 7.5], $1 \mathrm{M} \mathrm{NaCl}, 20 \mathrm{mM} \mathrm{KCl}, 1 \mu \mathrm{M}$ ONO-AE3-208, and protease inhibitor cocktail) and ultracentrifuged at $140,000 \times g$ for $30 \mathrm{~min}$ at $4^{\circ} \mathrm{C}$. The precipitate was resuspended in buffer $\mathrm{C}(30 \mathrm{mM} \mathrm{HEPES} \mathrm{[pH} 7.5$ ], $750 \mathrm{mM} \mathrm{NaCl}, 5 \mathrm{mM}$ imidazole, $1 \mathrm{mg} / \mathrm{mL}$ iodoacetamide, $1 \% \mathrm{n}$-dodecyl- $\beta$-D-maltoside [DDM], $0.2 \%$ cholesteryl hemisuccinate [CHS], $0.2 \%$ sodium cholate, $10 \mu \mathrm{M}$ ONO-AE3-208, and protease inhibitor cocktail), and stirred gently at $4^{\circ} \mathrm{C}$ for $2 \mathrm{~h}$. The insoluble components were removed via ultracentrifugation at $140,000 \times g$ for $30 \mathrm{~min}$ at $4^{\circ} \mathrm{C}$.

The supernatant was mixed with Ni-NTA resin (Qiagen) and stirred gently overnight at $4^{\circ} \mathrm{C}$. The resin was washed with $11 \mathrm{column}$ volumes of buffer D (30 mM HEPES [pH 7.5], $750 \mathrm{mM} \mathrm{NaCl}, 5 \mathrm{mM}$ imidazole, $0.02 \%$ sodium cholate, $0.1 \%$ DDM, $0.03 \%$ CHS, and $10 \mu \mathrm{M}$ ONO-AE3-208). EP4 was eluted in five column volumes of buffer $\mathrm{E}$ (30 mM HEPES [pH 7.5], $750 \mathrm{mM} \mathrm{NaCl,} 500 \mathrm{mM}$ imidazole, $0.02 \%$ sodium cholate, $0.1 \% \mathrm{DDM}, 0.03 \% \mathrm{CHS}$, and $10 \mu \mathrm{M}$ ONO-AE3-208). $\mathrm{CaCl}_{2}(2 \mathrm{mM})$ was added to the eluted sample and loaded onto a FLAG M1 affinity resin (Sigma-Aldrich) equilibrated in buffer $\mathrm{F}$ (30 mM HEPES [pH 7.5], $750 \mathrm{mM} \mathrm{NaCl,} 3 \mathrm{mM} \mathrm{CaCl}$, $0.02 \%$ sodium cholate, $0.1 \%$ DDM, $0.03 \% \mathrm{CHS}$, and $10 \mu \mathrm{M}$ ONO-AE3-208). Buffer $\mathrm{F}$ loaded on the resin was gradually replaced with buffer $\mathrm{G}$ (30 mM HEPES [pH 7.5], $750 \mathrm{mM} \mathrm{NaCl}, 3 \mathrm{mM} \mathrm{CaCl}_{2}, 0.2 \%$ lauryl maltose neopentyl glycol [MNG], 0.02\% CHS, and $10 \mu \mathrm{M}$ ONO-AE3-208). EP4 was eluted with two column volumes of buffer H $(20 \mathrm{mM} \mathrm{HEPES} \mathrm{[pH} \mathrm{7.5],100} \mathrm{mM} \mathrm{NaCl,} 0.01 \%$ MNG, $0.001 \%$ CHS, $10 \mu \mathrm{M}$ ONO-AE3-208, $5 \mathrm{mM}$ EDTA, and $0.2 \mathrm{mg} / \mathrm{mL}$ FLAG peptide) and two column volumes of buffer I (20 mM HEPES [pH 7.5], 100 mM NaCl, $0.01 \%$ MNG, $0.001 \%$ CHS, $10 \mu \mathrm{M}$ ONO-AE3-208, and 5 mM EDTA). The collected sample was supplemented with $100 \mu \mathrm{M}$ ONO-AE3-208 and $3 \mathrm{C}$ protease and then stirred gently overnight at $4{ }^{\circ} \mathrm{C}$. The amount of $3 \mathrm{C}$ protease was $30 \mu \mathrm{g}$ per mg sample protein. The sample was concentrated with Amicon Ultra-15 centrifugal filter units of 50,000 MWCO (Millipore) to $1 \mathrm{~mL}$. The sample was further purified via gel filtration on a Superdex 200 Increase 10/300 GL (GE Healthcare) with buffer J (20 mM HEPES [pH 7.5], $100 \mathrm{mM} \mathrm{NaCl}, 0.01 \% \mathrm{MNG}, 0.001 \% \mathrm{CHS}$, and $10 \mu \mathrm{M} \mathrm{PGE}_{2}$ ).

Construction, Expression, and Purification of Mini-Gs399

The DNA sequence of mini-Gs399 was synthesized based on the amino acid sequence of mini-Gs399, as reported previously (Carpenter and Tate, 2016), but the residue corresponding to Leu63 of Gs was mutated to the tyrosine from the original sequence of mini-Gs399. The mini-Gs399 sequence was inserted into pET21a (Novagen). In this construct, the N-terminal $6 \times$ His tag and TEV protease cleavage site were added to mini-Gs399. This plasmid is referred to as pET21a-mini-Gs399 in this study.

The plasmid was introduced into E. coli BL21-CodonPlus (DE3)-RIPL (Agilent Technologies). The cells were cultivated in TB supplemented with $100 \mathrm{mg} / \mathrm{L}$ ampicillin at $37^{\circ} \mathrm{C}$. After the optical density (OD) of the broth at $600 \mathrm{~nm}$ wavelength reached $0.6,500 \mu \mathrm{M}$ isopropyl $\beta$-D-1-thiogalactopyranoside (IPTG) was added and incubated overnight at $25^{\circ} \mathrm{C}$. The cells were harvested via centrifugation at $5,000 \times g$ for $15 \mathrm{~min}$ and stored at $-80^{\circ} \mathrm{C}$. The purification of mini-Gs399 was performed according to García-Nafría et al. (2018). The cells were suspended in buffer K (40 mM HEPES [pH7.5], $100 \mathrm{mM} \mathrm{NaCl}, 10 \%$ glycerol, $10 \mathrm{mM}$ imidazole, $5 \mathrm{mM}$ $\mathrm{MgCl}_{2}, 50 \mu \mathrm{M}$ GDP, $25 \mathrm{U} / \mathrm{L}$ DNase I, and protease inhibitor cocktail) and lysed via sonication (70 \% amplitude, $1 \mathrm{~s}$ ON $1.5 \mathrm{~s}$ OFF, 


\section{Structure} Article

$10 \mathrm{~min})$. The insoluble components were removed via centrifugation at $40,000 \times g$ for $45 \mathrm{~min}$. The supernatant was loaded onto a Ni Sepharose FF resin column (GE Healthcare). The resin was washed with 10 column volumes of buffer L (20 mM HEPES [pH7.5], $500 \mathrm{mM} \mathrm{NaCl}, 10 \%$ glycerol, $40 \mathrm{mM}$ imidazole, $1 \mathrm{mM} \mathrm{MgCl}_{2}$, and $50 \mu \mathrm{M} \mathrm{GDP}$ ), and the resin-binding protein was eluted in $3 \mathrm{column}$ volumes of buffer M (20 mM HEPES [pH7.5], $100 \mathrm{mM} \mathrm{NaCl}, 10 \%$ glycerol, $500 \mathrm{mM}$ imidazole, $1 \mathrm{mM} \mathrm{MgCl} 2$, and $50 \mu \mathrm{M} \mathrm{GDP}$ ). Dithiothreitol (DTT) $(1 \mathrm{mM})$ and TEV protease were added to the eluate. The amount of TEV protease was $50 \mu \mathrm{g}$ per mg sample protein. Then, the eluate was dialyzed overnight against buffer $\mathrm{N}(20 \mathrm{mM} \mathrm{HEPES}[\mathrm{pH} 7.5], 100 \mathrm{mM} \mathrm{NaCl}, 10 \% \mathrm{glycerol} 1 \mathrm{mM} \mathrm{MgCl}$, $10 \mu \mathrm{M}$ GDP) at $4{ }^{\circ} \mathrm{C}$. Imidazole $(20 \mathrm{mM})$ and Ni-NTA resin (Qiagen) were added to remove the resin-binding contaminant. The flow-through was collected. The resin was washed with 2.5 column volumes of buffer $\mathrm{N}$ and the flow-through was collected. The collected sample was concentrated with Amicon Ultra-15 centrifugal filter units of 10,000 MWCO (Millipore) to $5 \mathrm{~mL}$. The sample was further purified via gel filtration using a HiLoad 16/600 Superdex 200 pg (GE Healthcare) with buffer O (10 mM HEPES [pH 7.5], $100 \mathrm{mM} \mathrm{NaCl}, 10 \%$ glycerol, $1 \mathrm{mM} \mathrm{MgCl}_{2}, 10 \mu \mathrm{M} \mathrm{GDP}$, and $0.1 \mathrm{mM}$ Tris [2-carboxyethyl] phosphine hydrochloride [TCEP]).

Construction, Expression, and Purification of $\mathbf{G}_{1}$ and $\mathbf{G}_{\gamma_{2}}$

The DNA sequences of $G \beta_{1}$ and $G \gamma_{2}$ were inserted into the multi-cloning site of pFastBac Dual, which was then re-inserted in $\mathrm{pVL1393}$. This plasmid is referred to as $\mathrm{pVL1393-G} \beta_{1}-\mathrm{G} \gamma_{2}$.

Recombinant baculovirus was produced using the BestBac 2.0, v-cath/chiA deleted baculovirus cotransfection system (Expression Systems). Sf9 insect cells were cultured in PSFM-J1 medium supplemented with $2 \% \mathrm{FBS}, 50 \mathrm{units} / \mathrm{mL} \mathrm{penicillin,} 50 \mu \mathrm{g} / \mathrm{mL}$ streptomycin, and $0.5 \mu \mathrm{g} / \mathrm{mL}$ amphotericin B. After the cell density reached $3.5 \times 10^{6}$, the Sf9 cells were infected with the baculovirus at M.O.I. of 2 and cultivated at $27^{\circ} \mathrm{C}$ for 3 days. The cells were harvested via centrifugation at $7,000 \times g$ for 10 min and re-harvested via centrifugation at $8,000 \times g$ for $10 \mathrm{~min}$ after washing with PBS (-). The cells were suspended in $80 \%$ glycerol and stored at $-80^{\circ} \mathrm{C}$.

The cells were lysed in buffer $\mathrm{P}(10 \mathrm{mM}$ Tris [pH 7.5], $20 \mathrm{mM} \mathrm{KCl}, 0.1 \mathrm{mM} \mathrm{MgCl}, 10 \mathrm{mM}$ 2-mercaptoethanol, $10 \mu \mathrm{M}$ GDP, $1 \mathrm{mM}$ benzamidine, and $2.5 \mu \mathrm{M}$ leupeptine). The suspension was homogenized with a dounce homogenizer and ultracentrifuged at $177,000 \times \mathrm{g}$ for $30 \mathrm{~min}$ at $4^{\circ} \mathrm{C}$. The precipitate was suspended in buffer Q (10 mM HEPES [pH 7.5], $1 \mathrm{M} \mathrm{NaCl,} 20 \mathrm{mM} \mathrm{KCl}$, $10 \mathrm{mM} \mathrm{MgCl} 2,10 \mathrm{mM}$ 2-mercaptoethanol, $10 \mu \mathrm{M}$ GDP, $1 \mathrm{mM}$ benzamidine, and $2.5 \mu \mathrm{M}$ leupeptine), and ultracentrifuged at $177,000 \times \mathrm{g}$ for $15 \mathrm{~min}$ at $4^{\circ} \mathrm{C}$. The precipitate was resuspended in buffer $\mathrm{R}(20 \mathrm{mM} \mathrm{HEPES}$ [pH 7.5$], 100 \mathrm{mM} \mathrm{NaCl}, 5 \mathrm{mM}$ $\mathrm{MgCl}_{2}, 0.05 \% \mathrm{DDM}, 1 \%$ sodium cholate, $10 \mathrm{mM}$ 2-mercaptoethanol, $10 \mu \mathrm{M}$ GDP, $1 \mathrm{mM}$ benzamidine, and $2.5 \mu \mathrm{M}$ leupeptine), and stirred gently at $4^{\circ} \mathrm{C}$ for $1 \mathrm{~h}$. The insoluble components were removed via ultracentrifugation at $177,000 \times g$ for 30 min at $4^{\circ} \mathrm{C}$. Imidazole $(20 \mathrm{mM})$ and Ni-NTA resin were added to the supernatant and stirred gently overnight at $4^{\circ} \mathrm{C}$. The resin was washed with 16 column volumes of buffer $\mathrm{S}\left(20 \mathrm{mM} \mathrm{HEPES} \mathrm{[pH} \mathrm{7.5],} 100 \mathrm{mM} \mathrm{NaCl}, 5 \mathrm{mM} \mathrm{MgCl}_{2}, 0.05 \%\right.$ DDM, $1 \%$ sodium cholate, $10 \mathrm{mM} 2-$ mercaptoethanol, and $10 \mu \mathrm{M}$ GDP). Buffer S loaded on the resin was gradually replaced with buffer T (20 mM HEPES [pH 7.5], $100 \mathrm{mM} \mathrm{NaCl}, 1 \mathrm{mM} \mathrm{MgCl}_{2}, 0.05 \%$ DDM, $5 \mathrm{mM}$ 2-mercaptoethanol, and $\left.10 \mu \mathrm{M} \mathrm{GDP}\right)$. The resin was suspended in buffer T supplemented with $20 \mathrm{mM}$ imidazole and $3 \mathrm{C}$ protease, and then stirred gently overnight at $4^{\circ} \mathrm{C}$. The flow-through was collected. The resin was washed with 5 column volumes of buffer $T$ and the flow-through was collected. The collected sample was concentrated with Amicon Ultra-15 centrifugal filter units of 50,000 MWCO (Millipore) to $1.5 \mathrm{~mL}$. The sample was further purified via gel filtration on a Superdex 200 Increase 10/300 GL (GE Healthcare) with buffer U (20 mM HEPES [pH 7.5], $100 \mathrm{mM} \mathrm{NaCl,} 0.01 \%$ MNG, $0.001 \%$ $\mathrm{CHS}$, and $0.1 \mathrm{mM}$ TCEP).

\section{Construction, Expression, and Purification of Nb35}

The DNA sequence of Nb35 was synthesized based on the amino acid sequence of Nb35 (Rasmussen et al., 2011). The Nb35 sequence was inserted in pNY326. Sec signal peptide sequence was added at the N-terminus, and the TEV protease cleavage site, $6 \times$ His tag, and HA tag were added at the C-terminus. This plasmid is referred to as pNY326-Nb35 in this study.

The plasmid was introduced into Brevibacillus competent cells (Takara Bio). The cells were cultivated in 2SY medium supplemented with $50 \mathrm{mg} / \mathrm{L}$ neomycin at $30^{\circ} \mathrm{C}$ for two days. The cells were removed via centrifugation at $6,000 \times g$ for $15 \mathrm{~min}$.

The supernatant was supplemented with $60 \%$ ammonium sulfate and stirred at $4^{\circ} \mathrm{C}$ for $1 \mathrm{~h}$, following which it was centrifuged at $10,000 \times g$ for $20 \mathrm{~min}$ at $4^{\circ} \mathrm{C}$. The precipitate was dissolved in Tris-buffered saline (TBS) and dialyzed overnight against TBS at $4^{\circ} \mathrm{C}$. The sample was centrifuged at $15,000 \times g$ for $5 \mathrm{~min}$ at $4^{\circ} \mathrm{C}$. The supernatant was supplemented with $10 \mathrm{mM}$ imidazole and Ni-NTA resin and stirred gently at $4^{\circ} \mathrm{C}$ for 1.5 hour. The resin was transferred to an empty column and washed with 10 column volumes of buffer $\mathrm{V}$ (10 mM Tris [pH 7.5], $150 \mathrm{mM} \mathrm{NaCl}$, and $20 \mathrm{mM}$ imidazole). The resin-binding protein was eluted in two column volumes of buffer W (10 mM Tris [pH 7.5], $150 \mathrm{mM} \mathrm{NaCl}$, and $250 \mathrm{mM}$ imidazole). The eluted fractions were supplemented with $9 \mathrm{mg}$ TEV protease and dialyzed overnight against buffer $X(20 \mathrm{mM}$ Tris [pH 7.5], $150 \mathrm{mM} \mathrm{NaCl})$ at $4^{\circ} \mathrm{C}$. The sample was supplemented with $10 \mathrm{mM}$ imidazole and centrifuged at $15,000 \times g$ for $10 \mathrm{~min}$ at $4^{\circ} \mathrm{C}$. The supernatant was loaded onto a HisTrap HP column (GE Healthcare) and the flow-through fraction was collected. The column was washed with three column volumes of buffer $\mathrm{Y}$ (10 mM Tris [pH 7.5], $150 \mathrm{mM} \mathrm{NaCl}$, and $10 \mathrm{mM}$ imidazole) and the wash fractions were also collected. The collected fractions were concentrated using Amicon Ultra-15 centrifugal filter units of $10,000 \mathrm{MWCO}$ (Millipore) to $5 \mathrm{~mL}$. The sample was further purified via gel filtration using a HiLoad 16/600 Superdex 200 pg (GE Healthcare) with TBS.

PGE $_{2}$-EP4-Gs $\beta_{1} \gamma_{2}-\mathrm{Nb}_{3}$ Complex Formation and Purification

Purified EP4, mini-Gs399, $\mathrm{G} \beta_{1}-\mathrm{G} \gamma_{2}$, and $\mathrm{Nb35}$ were mixed at the molar ratio of 1: 1.2: 1.2: 2. The mixture was supplemented with $100 \mu \mathrm{M} \mathrm{PGE}_{2}, 0.1 \mathrm{U}$ apyrase, $0.0033 \% \mathrm{GDN}$, and $0.0013 \% \mathrm{CHS}$, and then incubated overnight at $4^{\circ} \mathrm{C}$. The sample was 


\section{$\infty$ CellPress}

\section{Structure

concentrated with Amicon Ultra-15 centrifugal filter units of 50,000 MWCO (Millipore) to $0.5 \mathrm{~mL}$. The sample was further purified via gel filtration on a Superdex 200 Increase 10/300 GL (GE Healthcare) with buffer Z (10 mM HEPES [pH 7.5], $100 \mathrm{mM} \mathrm{NaCl,} 0.00075 \%$ MNG, $0.00025 \%$ GDN, $0.000125 \% \mathrm{CHS}$, and $10 \mu \mathrm{M} \mathrm{PGE}$ ). The purified complex was concentrated with Amicon Ultra-4 centrifugal filter units of $50,000 \mathrm{MWCO}$ (Millipore) to $8.4 \mathrm{mg} / \mathrm{mL}$ (approximately $70 \mu \mathrm{M}$ ).

Cryo-EM Single Particle Analysis of the PGE ${ }_{2}-E P 4-G s \beta_{1} \gamma_{2}-N_{3} 35$ Complex

A holey carbon grid, Quantifoil grid of R0.6/R1.0 300 mesh copper (Quantifoil), was glow-discharged at $7 \mathrm{~Pa}$ with $10 \mathrm{~mA}$ for $10 \mathrm{~s}$ using a JEC-3000FC sputter coater (JEOL) prior to use. A 3- $\mu \mathrm{L}$ aliquot was applied onto the grid, blotted for $3.5 \mathrm{~s}$ with BlotForce of +10 in $100 \%$ humidity at $8^{\circ} \mathrm{C}$, and plunged into liquid ethane using a VitrobotMkIV (Thermo Fisher Scientific). Cryo-EM data collection for screening sample quality and grid conditions was performed using Glacios (Thermo Fisher Scientific) at $200 \mathrm{kV}$ with a Falcon3EC direct electron detector in the counting mode at the RIKEN RSC Cryo-EM facility (Hyogo, Japan). After several screening sessions, data were collected on an optimized grid using a Titan Krios G3i (Thermo Fisher Scientific) operated at $300 \mathrm{kV}$, equipped with a BioQuantum energy filter in zero-loss EFTEM NanoProbe mode with a $25 \mathrm{eV}$ energy selection slit and K3 direct electron detector (Gatan) in counting mode at the Cryo-EM Facility of the University of Tokyo (Tokyo, Japan). Movie stacks were acquired at $105,000 \times$ nominal magnification, with an accumulated dose of 50.0 electrons per $\AA^{2}$ over 50 frames. The pixel size of the specimen was $0.85 \AA$. The data were acquired using the beam-image shift method for $3 \times 3$ holes with a targeted stage shift to the central hole using the SerialEM software (Schorb et al., 2019). The defocus range was set from -0.6 to $-1.8 \mu \mathrm{m}$ with $0.15 \mu \mathrm{m}$ increments.

Cryo-EM data processing was performed using RELION 3.0.8- and 3.1- (Zivanov et al., 2018). Raw movie stacks were motion-corrected using motion correction implemented in RELION. The Contrast transfer function (CTF) parameters were determined using the CTFFIND4 program (Rohou and Grigorieff, 2015). The data processing workflow is summarized in Figure S2. A small dataset consisting of 1,467 movies from the screening session was used to obtain the initial model, and a monomeric mask for 3D classification and refinement was used to obtain a $3.9 \AA$ map as a consensus map after CtfRefine and Basian polishing using 456,991 particles for the large dataset consisting of 5,743 movies. The large dataset contains many particles close to each, similar to that in a dimer, as shown in the result of the reference-free 2D classification in Figure S2, possibly due to concentration after purification via gel filtration. Further classification without alignment and tau_fudge 2 value of 30 in two classes resulted in a better-looking model with $55.7 \%$ particles. For 254,883 particles, refinement with sidesplitter was performed to obtain a map with global resolution of $3.4 \AA$. Then, the focused classification without alignment and tau_fudge 2 value of 20 was performed for the region around the expected EP4-Gs interface site. The particle set consisting of 178,217 particles was selected for one of the four classes, and the subtracted signal was reverted for further refinement. The selected signal-reverted particle set was used for the 3D reconstruction using refined parameters from the previous 3D refinement job to obtain two half maps for the post-process job. The particle set was further processed with CtfRefine, Basian polishing, and another CtfRefine before the 3D refinement to obtain the final map. All the resolutions reported in this article were estimated using gold-standard Fourier shell correlation (FSC) between the two independently refined half maps (FSC $=0.143$ ). The cryo-EM maps have been deposited in the Electron Microscopy Data Bank. The statistics of EM data processing and refinement parameters are summarized in Table 1. Structural representations were generated using Chimera (Pettersen et al., 2004) and ChimeraX (Goddard et al., 2018).

\section{Model Building and Refinement}

The initial model was built from the crystal structure of the EP4-Fab001 complex (PDBID: 5YWY) (Toyoda et al., 2019) for EP4 and from the cryo-EM structure of the $A_{2 A}-G s \beta_{1} \gamma_{2}-N b 35$ complex for Gs $\beta_{1} \gamma_{2}$ and Nb35 (García-Nafría et al., 2018). The model was fitted to the EM density map using UCSF Chimera (Pettersen et al., 2004). Then, the model was further manually fitted using COOT (Emsley and Cowtan, 2004) and refined using phenix.real_space_refine (Afonine et al., 2018) within the PHENIX (Adams et al., 2010). The hydrogen atoms were added to the model during the refinement to keep the geometry of the side chains. The side chains of the residues corresponding to the poor density of the map were removed. The model geometry was validated using MolProbity (Davis et al., 2007) within the PHENIX. The final model statistics are shown in Table 1. The 3D models were deposited in the RCSB Protein Data Bank. Structural representations were generated using Pymol (Schrödinger), Chimera (Pettersen et al., 2004), and ChimeraX (Goddard et al., 2018).

\section{GloSensor cAMP Assay}

Human EP4 was inserted into pcDNA3.1 (Thermo Fisher Scientific) for expressing in HEK293 cells. The deletion sites and N-linked glycosylation site mutations were the same as in the Sf9 expression construct. The hemagglutinin and FLAG tag sequences were added at the N-terminus. This plasmid is referred to as pcDNA3.1-EP4 in this study. The site-directed mutations were introduced using polymerase chain reaction (PCR) using the designed primers.

HEK293 cells $\left(0.5 \times 10^{6} /\right.$ well) were cultured in 6-well tissue culture plates (Techno Plastic Products) at $37^{\circ} \mathrm{C}$ in the presence of $5 \%$ $\mathrm{CO}_{2}$. After $24 \mathrm{~h}, 50 \mathrm{ng}$ EP4 or EP4 mutant plasmid was transfected with $1.5 \mu \mathrm{g}$ pGloSensor-22F cAMP plasmid (Promega) using polyethyleneimine. After an additional $24 \mathrm{~h}$, the cells were collected and resuspended in $1 \times$ Hank's balanced salt solution (HBSS) (Gibco) with $1 \mathrm{mM}$ D-luciferin and $5 \mathrm{mM}$ HEPES $(\mathrm{pH} 7.5)$. Cells $\left(0.5 \times 10^{4}\right.$ cells were transferred to each well of the 96 well microplate (Greiner 


\section{Structure}

Bio-one). The cells were incubated for $2 \mathrm{~h}$ at room temperature in the dark. PGE $2(1 \mathrm{pM}-1 \mu \mathrm{M})$ and $1 \mu \mathrm{M}$ PF-04418948 (EP2 antagonist for inhibition of endogenous EP2 activities) were added, and luminescence was measured.

\section{QUANTIFICATION AND STATISTICAL ANALYSIS}

All cryo-EM data sets were processed using RELION 3.0.8 and 3.1. and were analyzed using the software listed in the Key Resources Table. The statistical information generated from data processing, refinement, and validation are shown in Table 1.

Sigmoid curves and EC50 values, described as mean \pm SEM (Figure 3C, 4B, and Table S1), were determined using Prism8. The experiments were performed in triplicates.

No other statistical analyses were performed. 
Structure, Volume 29

Supplemental Information

\section{Cryo-EM Structure of the Prostaglandin}

\section{E Receptor EP4 Coupled to G Protein}

Shingo Nojima, Yoko Fujita, Kanako Terakado Kimura, Norimichi Nomura, Ryoji Suno, Kazushi Morimoto, Masaki Yamamoto, Takeshi Noda, So Iwata, Hideki Shigematsu, and Takuya Kobayashi 


\section{SUPPLEMENTARY INFORMATION}

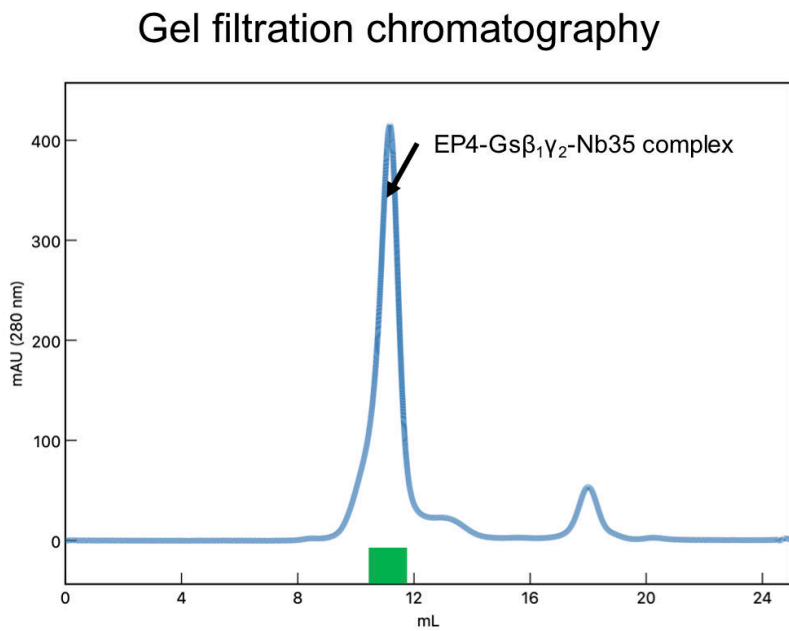

SDS-PAGE

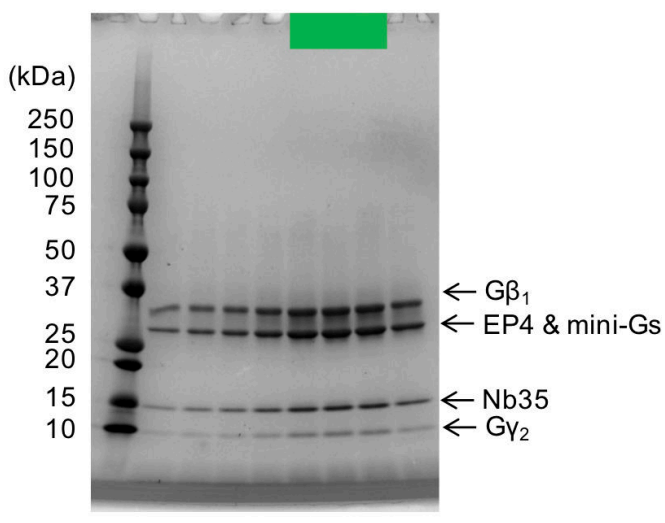

Figure S1. Purification of the PGE 2 -EP4-Gs $\beta_{1} \gamma_{2}-\mathrm{Nb35}$ complex, Related to Figure 1. Gel filtration chromatogram and SDS-PAGE of the purified PGE 2 -EP4-Gs $\beta_{1} \gamma_{2}-\mathrm{Nb} 35$ complex. Green area indicates the collected fractions. 
A

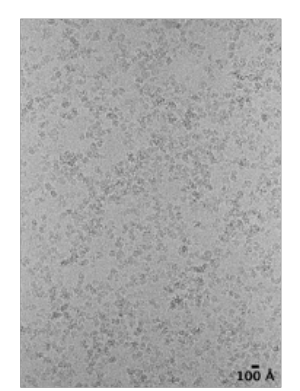

C

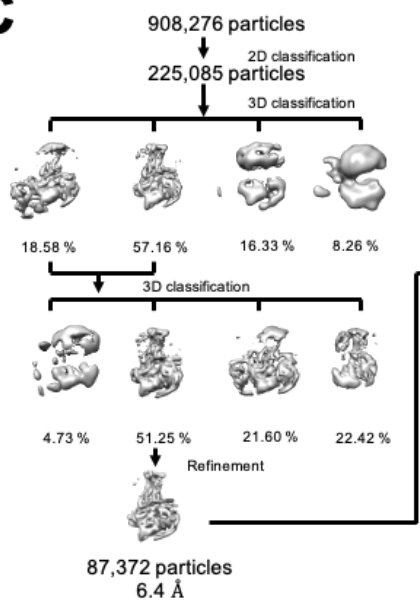

D
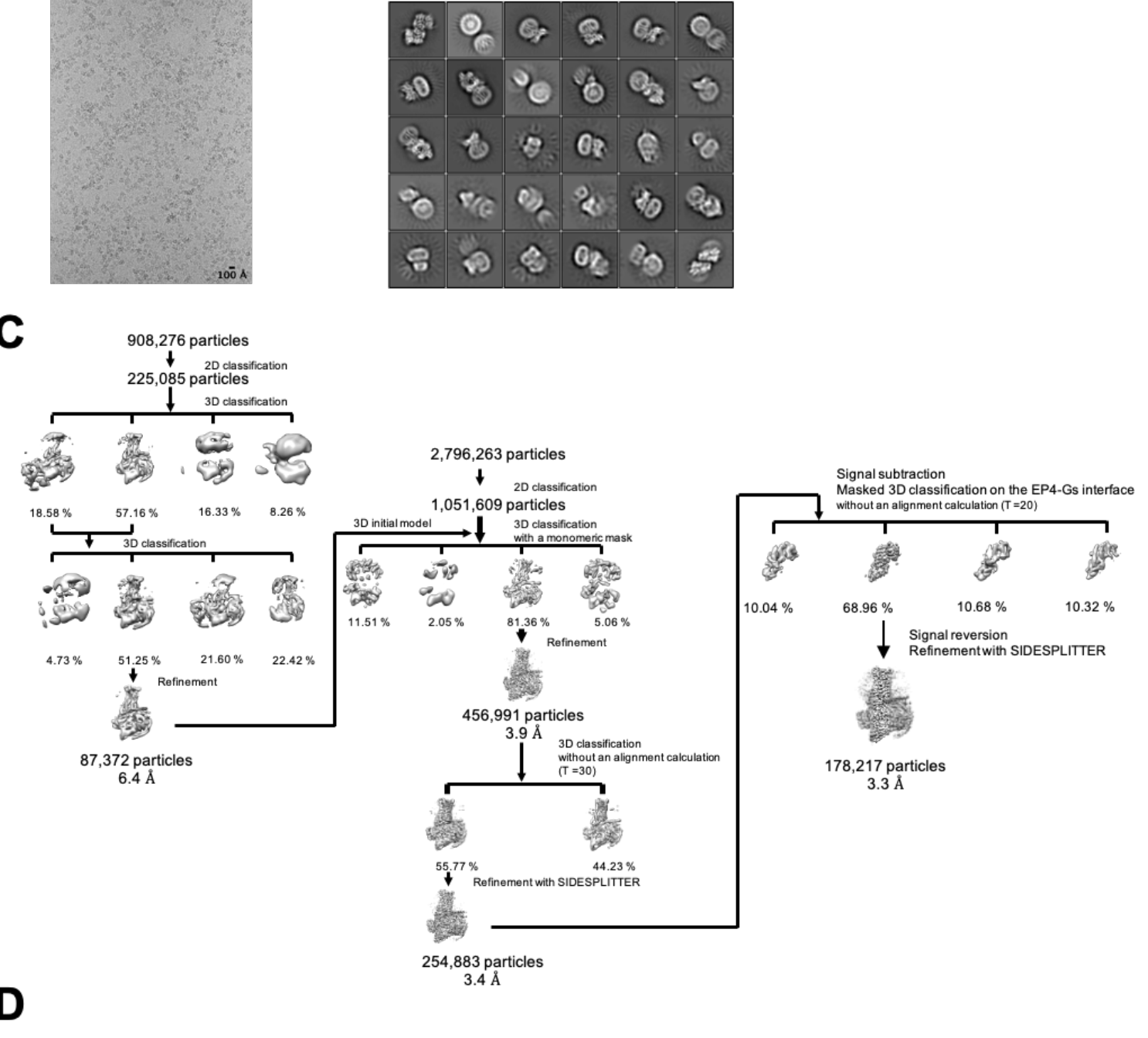

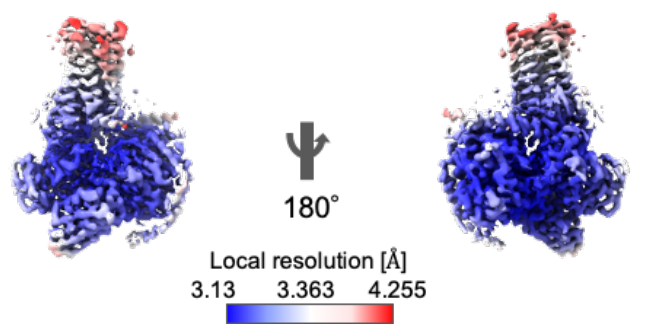

$\begin{array}{lll}3.13 & 3.363 & 4.255\end{array}$

Figure S2. Cryo-EM images and single particle analysis of the PGE 2 -EP4-Gs $\beta_{1} \gamma_{2}-\mathrm{Nb35}$ complex, Related to Figure 1 and STAR Methods. (A) Representative cryo-EM micrograph of $\mathrm{PGE}_{2}-\mathrm{EP} 4-$ Gs $\beta_{1} \gamma_{2}-\mathrm{Nb} 35$ complex. (B) 2D class averages of the complex. (C) Particle classification and refinement. (D) Local resolution map of the PGE 2 -EP4-Gs $\beta_{1} \gamma_{2}-\mathrm{Nb} 35$ complex. 


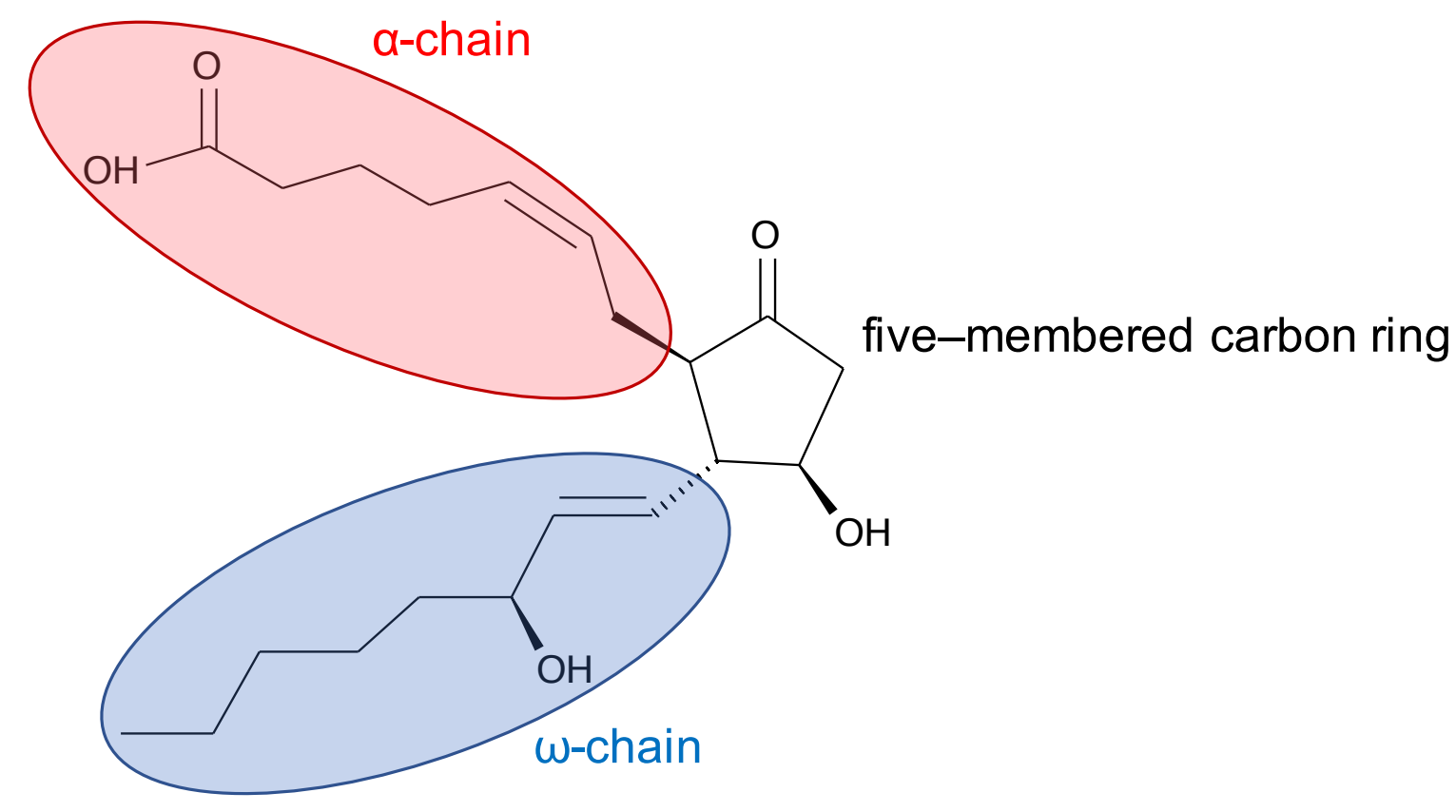

Figure S3. The structural formula of $\mathrm{PGE}_{2}$, Related to Figure 1 and 3. The chain circled by the red ring indicates $\alpha$-chain, and the chain circled by the blue ring indicates $\omega$-chain. 


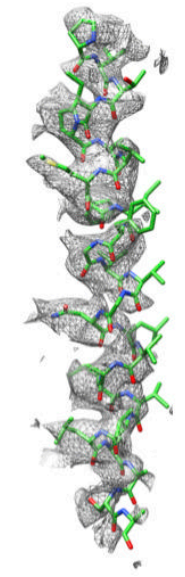

TM1

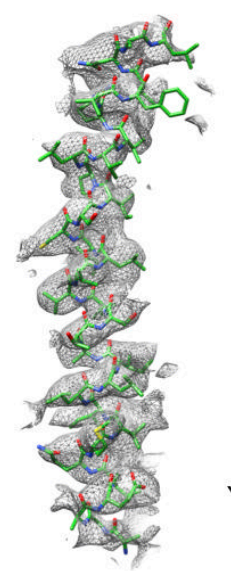

TM6

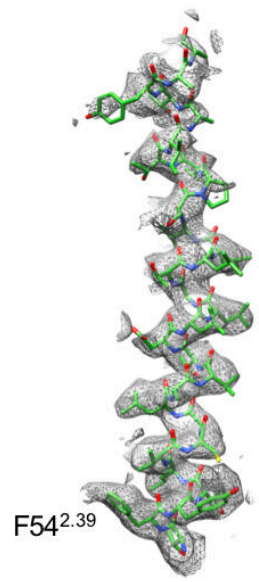

TM2

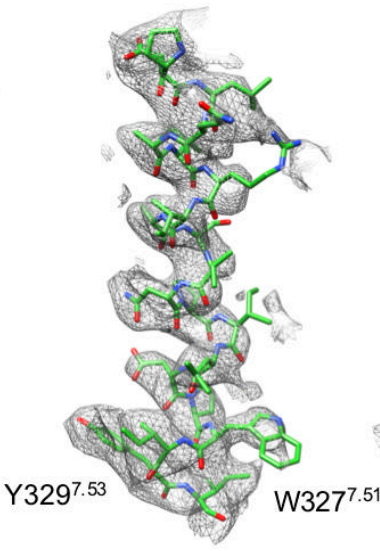

TM7

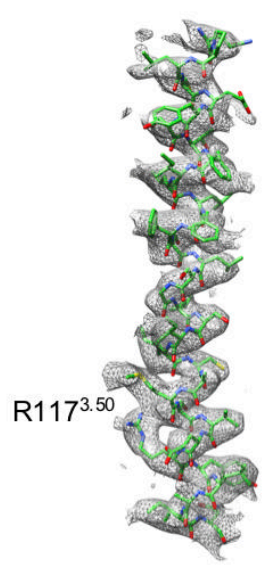

TM3

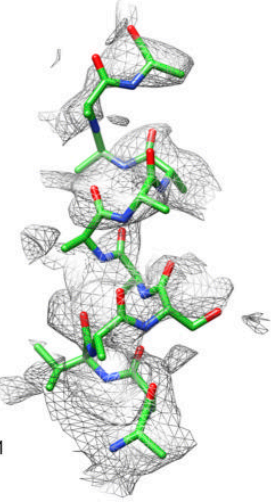

helix8

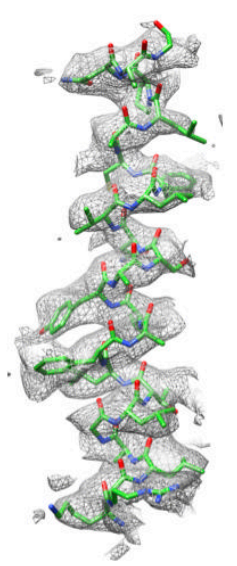

TM4

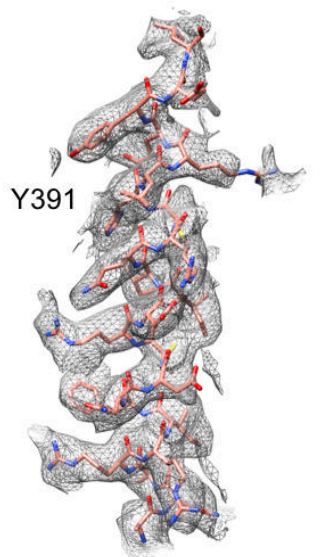

Gs-a5

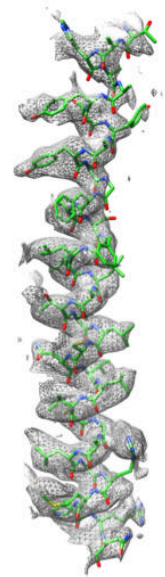

TM5

Figure S4. EM density of EP4, Gs, and PGE 2 , Related to Figure 1. The EM density map at global resolution of $3.3 \AA$ and models are shown for TM1-TM7 and helix 8 of EP4, $\alpha 5$ of Gs, and PGE 2 . The contour level of the map is set to 0.022 . 


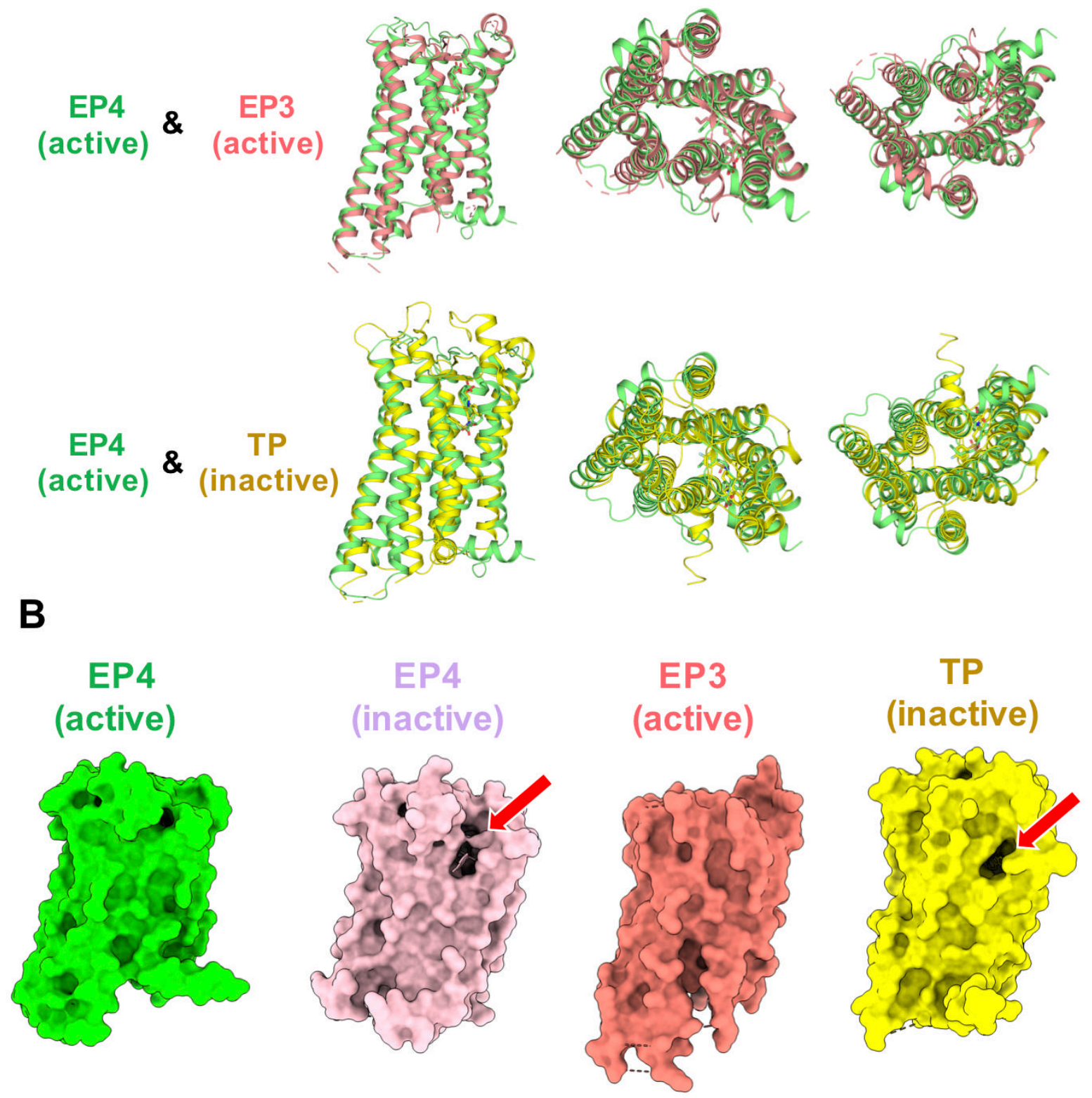

Figure S5. Structural comparison among prostanoid receptors, Related to Figure 3. (A) Comparison of the structures of active EP4 and active EP3 (PDB ID: 6AK3), and active EP4 and inactive TP (PDBID: 6IIU). Green: EP4, salmon: EP3, and yellow: TP. (B) The surface of active EP4, inactive EP4, EP3, and TP. Red arrows indicate the gap structure. 
Table S1. LogEC50s obtained in signaling analysis of EP4 site-directed mutants, Related to Figure 3 and 4.

\begin{tabular}{cc}
\hline & $\begin{array}{c}\text { LogEC50 } \\
\text { Mean } \pm \text { SEM }\end{array}$ \\
\hline No mutation & $-9.006 \pm 0.04048$ \\
P24A & $-7.069 \pm 0.02823$ \\
M27A & $-6.818 \pm 0.04317$ \\
K50A & $-7.798 \pm 0.02671$ \\
F54A & ND \\
T69A & $-8.138 \pm 0.01655$ \\
S73G & $-8.084 \pm 0.02732$ \\
T76A & $-7.375 \pm 0.04862$ \\
Y80A & $-6.721 \pm 0.0411$ \\
L99A & $-7.565 \pm 0.04234$ \\
S103A & $-8.239 \pm 0.05787$ \\
E116A & $-6.305 \pm 0.9801$ \\
R117A & ND \\
Y125A & $-7.348 \pm 0.01942$ \\
T168A & $-6.469 \pm 0.3968$ \\
W169A & ND \\
F171A & ND \\
L288A & $-7.685 \pm 0.05319$ \\
L312A & $-6.942 \pm 0.04485$ \\
I315A & $-7.74 \pm 0.04582$ \\
R316A & ND \\
N321A & $-6.721 \pm 0.0411$ \\
R333A & $-7.711 \pm 0.04534$ \\
\hline &
\end{tabular}

